\title{
Effect of Fe and Cr on the Macro/Micro Tribological Behaviours of Copper-Based Composites
}

\author{
Zhongyi Zhang ${ }^{1}$, Haibin Zhou ${ }^{1, *}$, Pingping Yao ${ }^{1, *}$, Kunyang Fan ${ }^{2}$, Yongqiang Liu ${ }^{3}$, Lin Zhao ${ }^{1}$, Yelong Xiao ${ }^{1}$, \\ Taimin Gong ${ }^{1}$ and Minwen Deng ${ }^{1}$ \\ 1 State Key Laboratory of Powder Metallurgy, Central South University, Changsha 410083, China; \\ zhangzhongyi1979@126.com (Z.Z.); zhaolin@csu.edu.cn (L.Z.); xiaoyelong87@126.com (Y.X.); \\ gongtaimin@csu.edu.cn (T.G.); 18874108043@163.com (M.D.) \\ 2 School of Mechanical Engineering, Chengdu University, Chengdu 610106, China; fankunyang123@126.com \\ 3 Aerospace System Engineering Shanghai, Shanghai 200000, China; heru689@163.com \\ * Correspondence: zhbtc22@126.com (H.Z.); yaopingpingxx@sohu.com (P.Y.); \\ Tel.: +86-731-88836983 (P.Y.); Fax: +86-731-88876614 (P.Y.)
}

check for updates

Citation: Zhang, Z.; Zhou, H.; Yao, P.; Fan, K.; Liu, Y.; Zhao, L.; Xiao, Y.; Gong, T.; Deng, M. Effect of Fe and Cr on the Macro/Micro Tribological Behaviours of Copper-Based Composites. Materials 2021, 14, 3417. https://doi.org/10.3390/ma14123417

Academic Editor: Andrzej Dziedzic

Received: 29 April 2021

Accepted: 15 June 2021

Published: 20 June 2021

Publisher's Note: MDPI stays neutral with regard to jurisdictional claims in published maps and institutional affiliations.

Copyright: (c) 2021 by the authors. Licensee MDPI, Basel, Switzerland. This article is an open access article distributed under the terms and conditions of the Creative Commons Attribution (CC BY) license (https:/ / creativecommons.org/licenses/by/ $4.0 /)$.

\begin{abstract}
Fe}$ and $\mathrm{Cr}$ are regarded as two of the most important friction components in $\mathrm{Cu}$-based composites ( $\mathrm{Cu}-\mathrm{BCs})$. In this study, the microstructural detection and micro- and macro-tribology evaluation of $\mathrm{Cu}-\mathrm{BC}$ s containing $\mathrm{Fe}$ and $\mathrm{Cr}$ were performed. The results indicated that both Fe and $\mathrm{Cr}$ formed diffusion interfaces with the copper matrix. Because of the generation of a defect interface layer, the $\mathrm{Cr} / \mathrm{Cu}$ interface exhibited a low bonding strength. Owing to the excellent binding interface between $\mathrm{Fe}$ and $\mathrm{Cu}$, the high coefficient of friction (COF) of $\mathrm{Fe}$, and the formation of a mechanical mixing layer promoted by $\mathrm{Fe}$, the $\mathrm{Cu}-\mathrm{BC}$ s containing Fe presented better friction performance under all braking energy per unit area (BEPUA) values. The main wear mechanism of $\mathrm{Cu}-\mathrm{BC}$ containing Fe and $\mathrm{Cr}$ changed from abrasion to delamination with an increase in BEPUA, and the delamination of $\mathrm{Cu}-\mathrm{BCs}$ containing Fe was induced by breaks in the mechanical mixed layer (MML).
\end{abstract}

Keywords: abrasion component; interface; tribological performance; Cu-based composites

\section{Introduction}

$\mathrm{Cu}$-based composites for brake applications are generally composed of three different components: matrix components, lubrication components, and friction components [1]. The matrix components control the basic physical and mechanical properties. Copper is widely used as a matrix component because of its good ductility, electrical conductivity, and thermal conductivity [2-4]. The lubrication components are used for smoothing the braking process and the friction components, which determine tribological performance, play an important role in $\mathrm{Cu}-\mathrm{BCs}$ [5-7].

Fe and $\mathrm{Cr}$ are the most crucial friction components owing to their low solubility and high wettability with the copper matrix, which effectively increase the temperature resistance, resistance to plastic deformation, coefficient of friction, and wear resistance of $\mathrm{Cu}-\mathrm{BCs}$. Therefore, $\mathrm{Cu}-\mathrm{BC}$ s containing the friction components mentioned above are utilized in high-energy braking systems for aerospace, high-speed trains, and heavy-duty engineering machinery applications [8,9].

To analyse the role of Fe and $\mathrm{Cr}$ for $\mathrm{Cu}-\mathrm{BC}$ in detail, several studies have been carried out. Peng et al. $[10,11]$ determined that a high Fe content helps the formation of oxidative film, thereby improving the wear resistance and stability of the coefficient of friction (COF) of $\mathrm{Cu}-\mathrm{BC}$ s during braking. Zhang et al. [12] reported the friction characteristics of Fe types in $\mathrm{Cu}-\mathrm{BCs}$, and the results showed that the performance of reduced Fe powder was better than that of carbonyl Fe powder and flake Fe powder thanks to the former's ability to maintain a high and stable COF under high-energy braking. Zhong et al. [13] studied the effects of Fe content on the tribological performance of $\mathrm{Cu}-\mathrm{BC}$, and the conclusions 
showed that an increasing Fe content contributed to friction torque stabilization, $\mathrm{COF}$ growth, and wear reduction. However, it was easy to produce a sharp drop in the wear performance of $\mathrm{Cu}-\mathrm{BCs}$ with the addition of excess Fe. Shen [14] studied mechanical properties of $\mathrm{Cu}-\mathrm{Fe}$ interfaces, and the results showed that $\mathrm{Cu}(111) / \mathrm{Fe}(110)-\mathrm{NW}$ and $\mathrm{Cu}(111) / \mathrm{Fe}$ (110)-KS interfaces have higher strength, which increases the tensile strength of the materials. Wang [15] studied the relationship between the tensile property and the $\gamma$-Fe/Cu interface, and the conclusions showed that the $\mathrm{Fe}(110) / \mathrm{Cu}(110)$ interface shows a higher strength metal bond, which showed that Fe accelerate nucleation and growth of $\mathrm{Cu}$.

The functions of $\mathrm{Cr}$ are different from those of $\mathrm{Fe}$. $\mathrm{Cr}$ is the hardest metal in nature; at the same time, $\mathrm{Cr}$ has a high melting point, strong corrosion resistance, and oxidation resistance. This type of friction component is utilized for raising hardness, improving electrical properties, and strengthening oxidation resistance of $\mathrm{Cu}-\mathrm{BCs}[16,17]$. Gao [18] studied the influence of $\mathrm{Cr}$ content on the friction and wear properties of $\mathrm{Cu}-\mathrm{BCs}$, and the results showed that COF gradually increased with $\mathrm{Cr}$ content in the range of 3-5 wt.\%. However, Fang [19], who obtained opposite results, noted that an increase in Cr content reduced the wear of $\mathrm{Cu}-\mathrm{BCs}$, but also decreased $\mathrm{COF}$, especially under conditions of 15-20 wt.\% Cr content. Fu et al. [20] argued that $\mathrm{Cr}$ not only contributed to an increase in $\mathrm{COF}$, but also enhanced wear resistance. Chen [21] studied that the relationship between the tensile strength and $\mathrm{Cu} / \mathrm{Cr}$ interface of $\mathrm{Cu}-\mathrm{Cr}-\mathrm{Zr}$ alloy, and the results showed that a semi-coherent interface was formed of $\mathrm{Cu} / \mathrm{Cr}$, which increased the strength of $\mathrm{Cu}-\mathrm{Cr}-\mathrm{Zr}$ alloy and suppressed the formation of dislocations.

In summary, the current research mainly focuses on the influence of $\mathrm{Cr}$ and $\mathrm{Fe}$ on mechanical properties and the macro friction and wear performance of $\mathrm{Cu}-\mathrm{BCs}$, whereas the intrinsic micro tribology behaviours of $\mathrm{Fe}, \mathrm{Cr}$, and their interface with matrix are still not fully understood. In addition, influences of $\mathrm{Fe}$ and $\mathrm{Cr}$ on high energy braking performance of $\mathrm{Cu}-\mathrm{BCs}$ are not clear as well. Therefore, it is necessary to carry out a comprehensive and detailed study on micro-macro perspectives on the action mechanisms of $\mathrm{Fe}$ and $\mathrm{Cr}$ in $\mathrm{Cu}-\mathrm{BC}$. This study aims to systematically investigate the differences between $\mathrm{Fe}$ and $\mathrm{Cr}$ regarding their interface characteristics with the copper matrix, as well as their micro and macro tribology properties. The purpose of this research is to clarify in detail the influence of friction components $\mathrm{Fe}$ and $\mathrm{Cr}$ on tribology behaviour of $\mathrm{Cu}-\mathrm{BCs}$, specially under high braking energy conditions. The findings of this work will contribute to the development of high performance braking materials.

\section{Experimental Section}

\subsection{Materials}

Table 1 lists the compositions of $\mathrm{Cu}-\mathrm{BC}$ s prepared by the powder metallurgy method. The raw powders included reduced $\mathrm{Fe}$ and $\mathrm{Cr}$ with $99.85 \%$ purity manufactured by Jinjiang Powder Metallurgy Factory (Quanzhou, China), electrolytic Cu powder $(99.98 \%)$ from the Huahao company (Chongqing, China), and KS150-600SP graphite powder of $97 \%$ purity (Imerys Graphite \& Carbon Company, Paris, France); these powders were used as the raw materials. The characteristic parameters of these powders are listed in Table 2.

Table 1. Chemical compositions of $\mathrm{Cu}-\mathrm{BCs}$ (vol. \%).

\begin{tabular}{ccccc}
\hline & Cu & Fe & Cr & Graphite \\
\hline $1 \#$ & 90 & 10 & $\backslash$ & $\backslash$ \\
$2 \#$ & 90 & $\backslash$ & 10 & $\backslash$ \\
$3 \#$ & 50 & 10 & $\backslash$ & 40 \\
$4 \#$ & 50 & $\backslash$ & 10 & 40 \\
\hline
\end{tabular}


Table 2. Characteristics of the raw powders.

\begin{tabular}{ccc}
\hline Raw Powders & Element Content & Particle Size \\
\hline $\mathrm{Cu}$ & $\mathrm{Cu} \geq 99.98 \mathrm{wt} . \%$ & $<74 \mu \mathrm{m}$ \\
$\mathrm{Fe}$ & $\mathrm{Fe} \geq 99.8 \mathrm{wt} . \%$ & $<74 \mu \mathrm{m}$ \\
$\mathrm{Cr}$ & $\mathrm{Cr} \geq 99.8 \mathrm{wt} . \%$ & $<74 \mu \mathrm{m}$ \\
Graphite & $\mathrm{C} \geq 97.0 \mathrm{wt} \%$ & $150-600 \mu \mathrm{m}$ \\
\hline
\end{tabular}

The production process for $\mathrm{Cu}-\mathrm{BC}$ s is presented in Figure 1. The preparation process of the experimental samples was as follows: (1) weighing raw powders according to the formula in Table 1; (2) mixing raw powders in a roller mixer for $6 \mathrm{~h}$; (3) pressing the mixed powders in moulds under a pressure of $400 \mathrm{MPa}$; and (4) sintering green compacts using home-made pressure sintering furnace with a pressure of $2.5 \mathrm{MPa}$ at $970{ }^{\circ} \mathrm{C}$ for $3 \mathrm{~h}$. During the sintering process, hydrogen was selected as a protective atmosphere to prevent oxidation of metal at a high temperature.

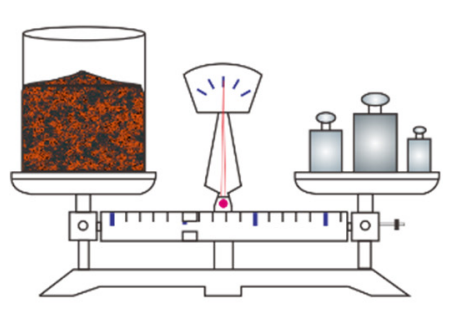

Weighing

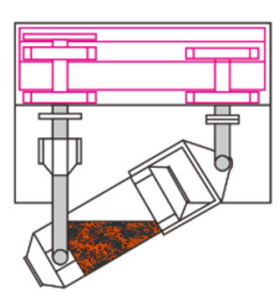

Mixing

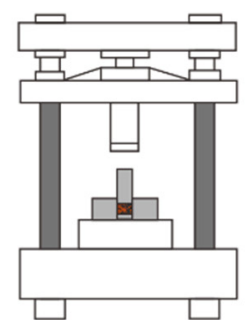

Compacting

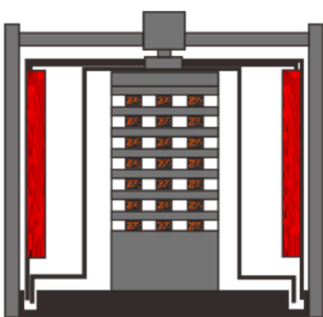

Sintering

Figure 1. Preparation process for $\mathrm{Cu}-\mathrm{BCs}$.

In order to ensure that $\mathrm{Cu}-\mathrm{Fe}$ and $\mathrm{Cu}-\mathrm{Cr}$ have roughly the same relative density, the ratio of $\rho / \rho_{\text {th }}$ needs to be calculated. It is calculated as follows:

$$
\rho_{t h}=\frac{\rho_{1} V_{1}+\rho_{2} V_{2}}{V_{1}+V_{2}}
$$

where $\rho_{1}, \rho_{2}$-component density; $V_{1}, V_{2}$ —component volume.

$$
\rho_{r}=\frac{\rho}{\rho_{\text {th }}}
$$

where $\rho_{r}$-relative density; $\rho$-material measured density; $\rho_{t h}$-theoretical density.

After sintering is complete, densities $(\rho)$ of the $\mathrm{Cu}-\mathrm{BC}$ s were measured according to the drainage method. $\rho_{t h}$ is calculated according to Equation (1). The relative density $\left(\rho / \rho_{t h}\right)$ and density $(\rho)$ as shown in Table 3.

Table 3. Relative density and density of $\mathrm{Cu}-\mathrm{BCs}$.

\begin{tabular}{ccccc}
\hline No. & Sample & $\rho_{\text {th }}$ & $\rho\left(\mathrm{g} \mathrm{cm}^{-3}\right)$ & $\rho_{\boldsymbol{r}}$ \\
\hline $1 \#$ & $\mathrm{Cu}-\mathrm{Fe}$ & 8.55 & 8.12 & 0.918 \\
$2 \#$ & $\mathrm{Cu}-\mathrm{Cr}$ & 8.14 & 7.42 & 0.912 \\
$3 \#$ & $\mathrm{Cu}-\mathrm{Fe}-\mathrm{C}$ & 6.17 & 4.96 & 0.804 \\
$4 \#$ & $\mathrm{Cu}-\mathrm{Cr}-\mathrm{C}$ & 5.20 & 4.12 & 0.793 \\
\hline
\end{tabular}




\subsection{Experimental Methods}

Microstructural characterizations of the experimental samples and bonding interfaces were surveyed using a Leica-Q550 metallurgical microscope (Leica Camera AG, Wetzlar, Germany) and a scanning electron microscope (FEI Quanta 250 FEG SEM, FEI company, Hillsboro, OL, USA) equipped to examine the energy dispersion spectrum.

The micro tribological properties of the $\mathrm{Fe}$ and $\mathrm{Cr}$ phases and interface strength were measured by a micro friction tester (manufactured by CSM instrument, Acacias, Switzerland). The samples were machined into cylinders about $25 \mathrm{~mm}$ in diameter and then polished until surface roughness values $(\mathrm{Ra})$ of 1.2 were attained before testing.

The micro-friction test was carried out in three stages: pre-scan of the indenter, friction test, and data calculation. Because the experimental procedures were described in our previous work, the detailed test procedures will not be elaborated on in detail here [22]. In this paper, we used the same test method and simplified the test parameters. Table 4 lists the key parameters for the micro-friction tests. The COF of tests was measured as

$$
\mu=\frac{F_{t}}{F_{n}}
$$

where $F_{t}$ is the tangential force and $F_{n}$ is the normal force. The detailed test parameters are shown in Table 4.

Table 4. Microfriction test parameters for different areas.

\begin{tabular}{cc}
\hline Test Area & Fe/Cr Phases and Their Interface with Matrix \\
\hline & Radius of indenter: $10 \mu \mathrm{m}$, load: $0.3 \mathrm{~N} / 0.5 \mathrm{~N}$ \\
Test parameters & Sliding distance: $100 \mu \mathrm{m}$, sliding speed: $200 \mu \mathrm{m} / \mathrm{min}$ \\
Relative humidity: $50 \%$ \\
\hline
\end{tabular}

The influences of $\mathrm{Fe}$ and $\mathrm{Cr}$ on the macro tribological properties of $\mathrm{Cu}-\mathrm{BC}$ s under different BEPUA were evaluated by a braking tester (MM-3000, Shuntong electromechanical technology research institution, $\mathrm{Xi}^{\prime}$ an, China), as shown in Figure 2. Next, $30 \mathrm{CrMnSiV}$ steel alloys containing $0.27-0.34 \% \mathrm{C}, 0.8-1.1 \% \mathrm{Mn}, 0.8-1.1 \% \mathrm{Cr}, 0.3-0.4 \% \mathrm{~V}, 0.9-1.2 \% \mathrm{Si}$, $p \leq 0.0035 \%$, and $\mathrm{S} \leq 0.03 \%$ were adopted as counterparts, which shows a Rockwell hardness of 39-42. All samples and counterparts were machined into rings with an inner diameter of $53 \mathrm{~mm}$ and an outer diameter of $75 \mathrm{~mm}$. These rings were then polished until surface roughness values ( $\mathrm{Ra}$ ) of 1.2 were attained before testing. The macro friction parameters are given in Table 5. According to the test parameters, the test conditions can be divided into low BEPUA ( $3000 \mathrm{rpm}, 8.47 \mathrm{~J} / \mathrm{mm}^{2}$ ), medium BEPUA (5000 rpm, $\left.23.50 \mathrm{~J} / \mathrm{mm}^{2}\right)$, and high BEPUA $\left(46.10 \mathrm{~J} / \mathrm{mm}^{2}\right)$.

Table 5. The test parameters of macro-friction.

\begin{tabular}{cccc}
\hline Brake Pressure/MPa & Inertia/kg $\cdot \mathbf{m}^{2}$ & Rotation Speed/rpm & $\begin{array}{c}\text { Theoretical } \\
\text { BEPUA/J/mm }\end{array}$ \\
\hline 0.6 & 0.35 & $3000 / 5000 / 7000$ & $8.47 / 23.50 / 46.10$ \\
\hline
\end{tabular}




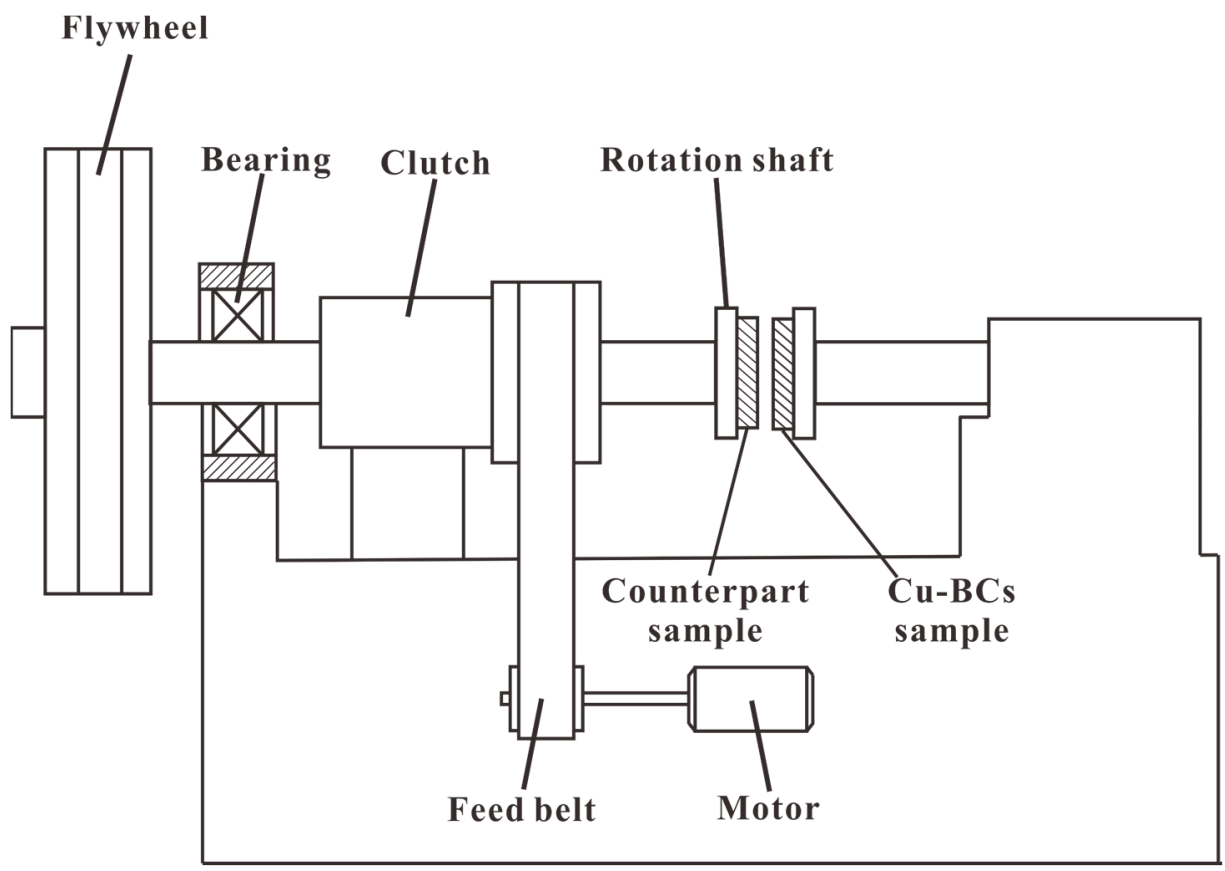

Figure 2. Structure chart of the MM-3000 friction tester.

\section{Results and Discussion}

\subsection{Morphology, Microstructure, and Interface Characteristics}

The shape of Fe and Cr particles was generally similar, but the morphologies were different. The Fe powder had a typical spongy and spherical-like structure. However, compared with the Fe powder, the $\mathrm{Cr}$ powder possessed a denser and smoother particle morphology, as shown in Figure 3b, which was mainly caused by the small volume shrinkage during the reduction of $\mathrm{Cr}$.
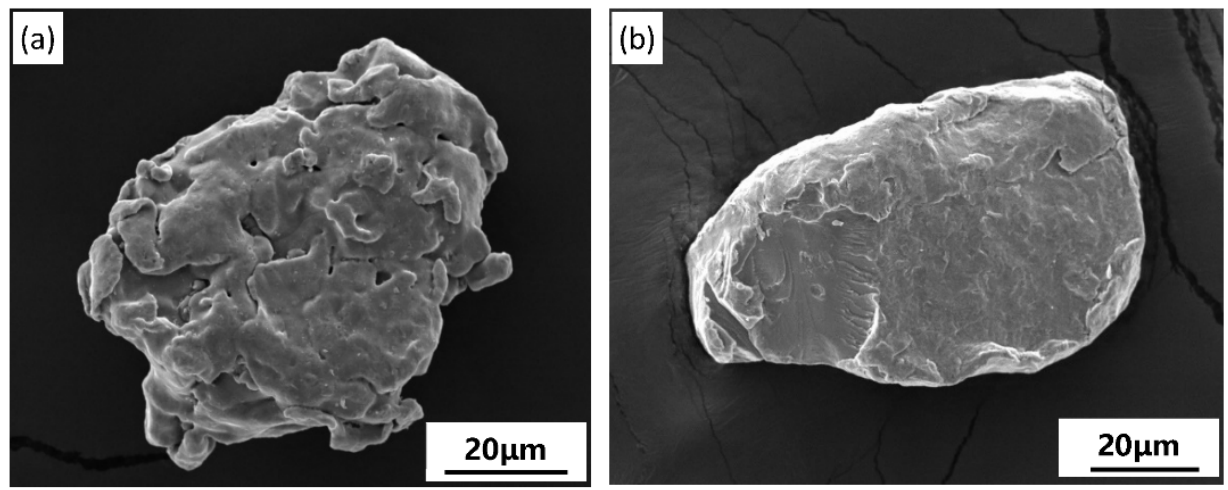

Figure 3. Typical morphology of the Fe and Cr particles: (a) Fe particle and (b) Cr particle.

Micrographs of the $\mathrm{Cu}-\mathrm{Fe}$ composite are shown in Figure $4 \mathrm{a}$, which indicates that the grey Fe particles were uniformly distributed in the matrix. Figure $5 b$ provides further illustrations of the Fe/Cu interface. Notably, a tightly bonded interface formed between the Fe phase and $\mathrm{Cu}$ matrix because of the excellent wettability between them. Nevertheless, a small number of microvoids with high curvature were present on the interface owing to vacancy aggregation, which is caused by the Kirkendall effect. 

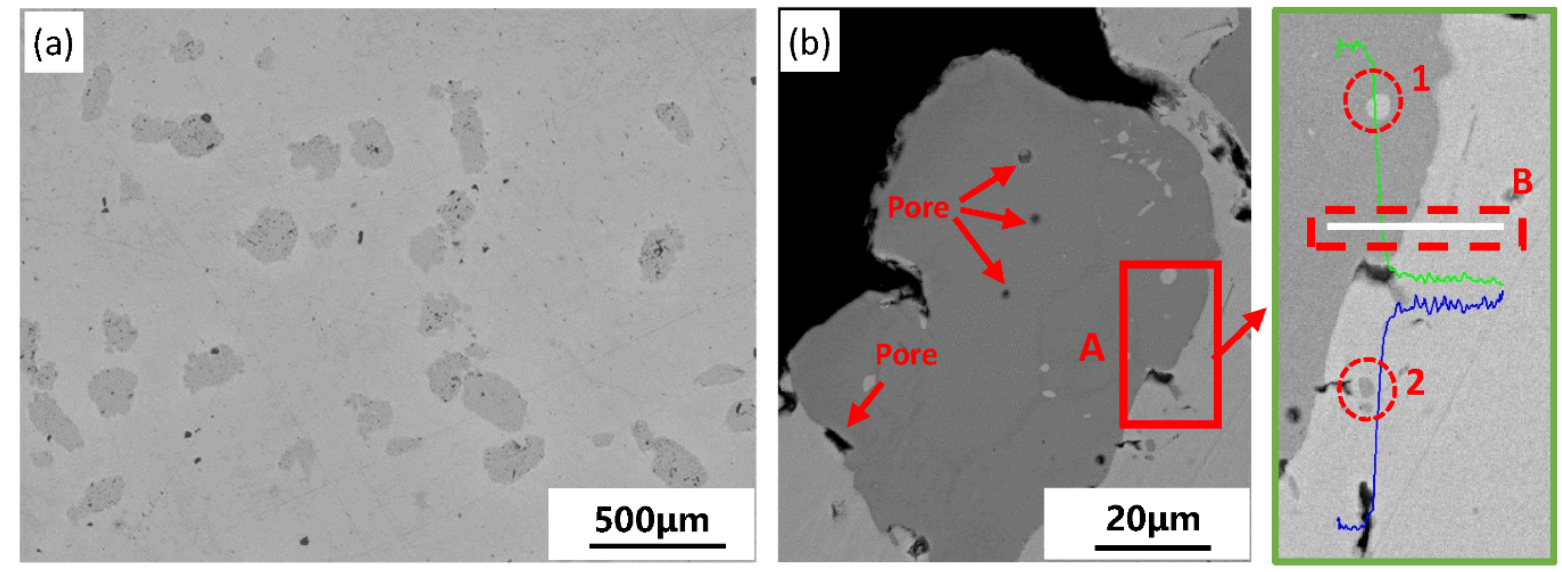

Figure 4. Microstructure of the $\mathrm{Cu}-\mathrm{Fe}$ sample (a) and the characteristics of the $\mathrm{Fe} / \mathrm{Cu}$ interface (b).
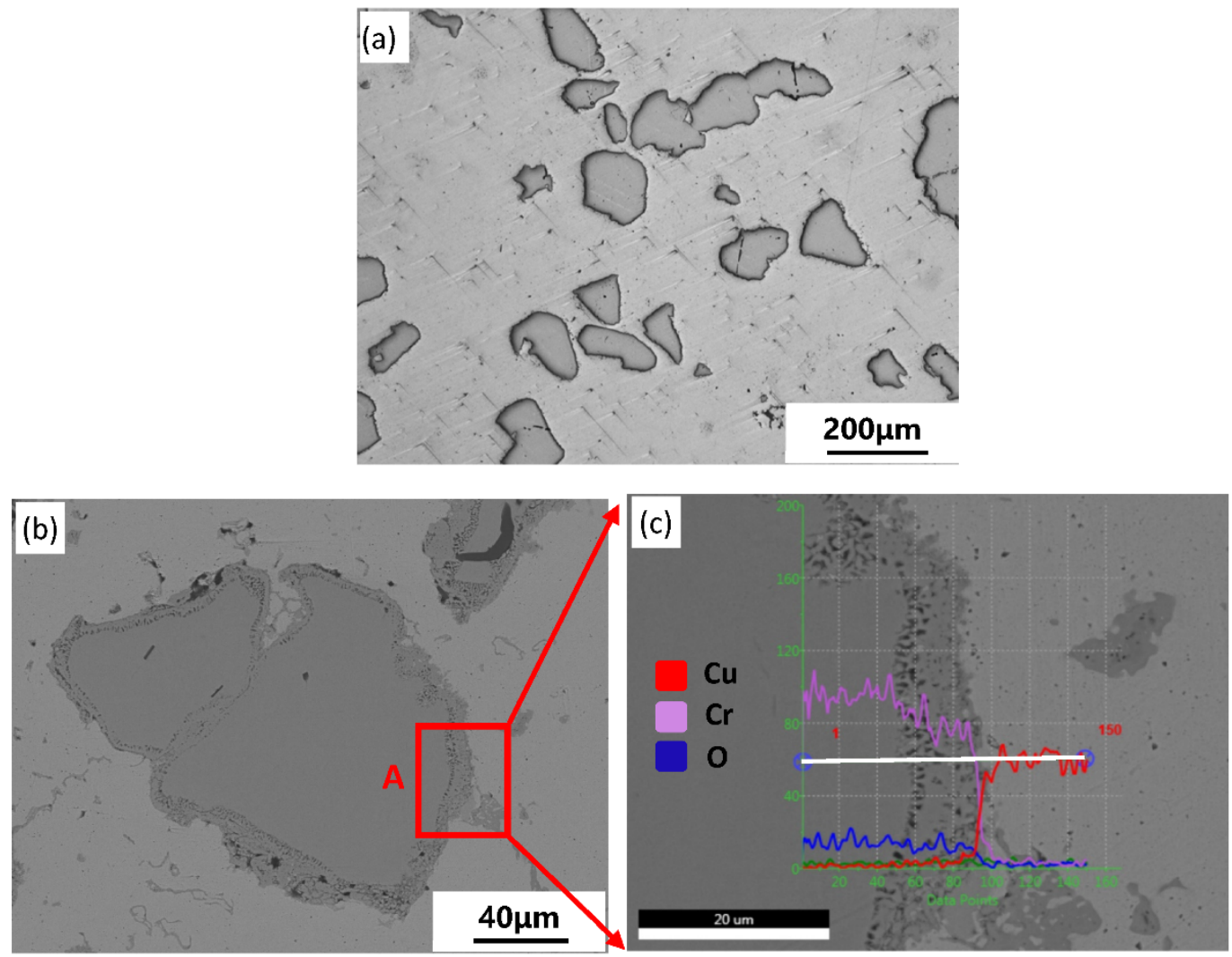

Figure 5. Microstructure of the $\mathrm{Cu}-\mathrm{Cr}$ sample and interface characteristics. (a) Microstructure of the $\mathrm{Cu}-\mathrm{Cr}$ sample (A2); (b) enlarged image of the $\mathrm{Cr}$ friction component; (c) characteristics of the $\mathrm{Cr} / \mathrm{Cu}$ interface.

The interface morphology of the $\mathrm{Fe} / \mathrm{Cu}$ interface is shown in detail in Figure $4 \mathrm{~b}$. According to the EDS scanning results of line $\mathrm{B}$, the content of $\mathrm{Cu}$ and Fe changed rapidly in the interface, indicating no formation of an obvious diffusion layer in this area. However, the EDS analyses of point 1 (light $\mathrm{Cu}$-rich phase inside Fe) and point 2 (dark Fe-rich phase inside $\mathrm{Cu}$ matrix), as shown in Table 6, indicated that mutual diffusion between Fe and $\mathrm{Cu}$ occurred during the sintering process. The generation of $\mathrm{Cu}$-rich phases and Fe-rich phases was caused by a decrease in solid solubility between the two elements after the cooling process based on the $\mathrm{Fe}-\mathrm{Cu}$ phase diagram [23].

Figure 5 shows the interface characteristics and the microstructure of the $\mathrm{Cu}-\mathrm{Cr}$ composite. There was an obvious interface layer generated in the $\mathrm{Cr} / \mathrm{Cu}$ interface, showing 
a completely different structure from the $\mathrm{Fe} / \mathrm{Cu}$ interface. To determine the detailed features of the $\mathrm{Cr} / \mathrm{Cu}$ interface, we employed micrography at high magnification, as shown in Figure 5c. The interface layer showed a pore-filled structure with 7-10 $\mu \mathrm{m}$ thickness. The EDS results of line 3, on which the $\mathrm{Cr}$ and $\mathrm{Cu}$ composition gradients changed, indicate that the mutual diffusion between $\mathrm{Cr}$ and $\mathrm{Cu}$ was stronger than that between $\mathrm{Fe}$ and $\mathrm{Cu}$.

Table 6. EDS point results for the $\mathrm{Cu}-\mathrm{Fe}$ interface in Figure $4 \mathrm{~b}$ area A (at.\%).

\begin{tabular}{ccc}
\hline Point Number & Cu & Fe \\
\hline 1 & 60.34 & 39.66 \\
2 & 18.71 & 81.29 \\
\hline
\end{tabular}

According to the analysis mentioned above, both $\mathrm{Fe}$ and $\mathrm{Cr}$ formed a diffusion bonding interface with the matrix. However, there were noteworthy differences between the two kinds of interfaces in morphology and structure owing to differences in the diffusion rate. For $\mathrm{Cu}-\mathrm{Fe}$ composites, with an increase in the sintering temperature, the crystals of $\mathrm{Fe}$ changed from BCC structures to FCC structures, leading to an improvement in the solid solubility between $\gamma$-Fe and $\mathrm{Cu}$. However, the extremely low inter-diffusion rate between the two phases resulted in the formation of a diffusion bonding interface without the interface layer. For $\mathrm{Cu}-\mathrm{Cr}$ composites, the formation of interface morphology may lead by a combination of multiple mechanisms. The first influence factor is the inequality diffusion between $\mathrm{Cu}$ and $\mathrm{Cr}$. When the temperature was raised to $970{ }^{\circ} \mathrm{C}$, the solid solution of $\mathrm{Cu}$ within the $\mathrm{Cr}(\mathrm{bcc})$ phase was less than 0.25 at.\%, but the maximum solid solution of $\mathrm{Cr}$ within the $\mathrm{Cu}$ (fcc) phase was close to 0.9 at.\% [24]. In addition, according to the diffusion constants and activation energies of diffusion at sintering temperature, the bulk diffusivity of $\mathrm{Cr}$ towards $\mathrm{Cu}\left(D_{\mathrm{Cr}-\mathrm{Cu}}: 2.32 \times 10^{-13}\right)$ was two orders of magnitude higher $\left(D_{\mathrm{Cu} u \mathrm{Cr}}\right.$ : $6.93 \times 10^{-15}$ ) than that of $\mathrm{Cu}$ towards $\mathrm{Cr}$. Therefore, the diffusion fluxes of $\mathrm{Cr}$ within $\mathrm{Cu}$ were considerably higher than those of $\mathrm{Cu}$ in $\mathrm{Cr}$. However, owing to a low mutual solubility between $\mathrm{Cr}$ and $\mathrm{Cu}$, the effect of Kirkendall in interface morphology is limited. In this condition, the generation of pores in $\mathrm{Cr} / \mathrm{Cu}$ interface may also be attributed to the precipitation of supersaturated hydrogen from metals, or the producing of undischarged water vapor formed by the reduction of oxide of $\mathrm{Cr}$ particles during the sintering process. Eventually, a pore-filled diffusion layer was formed in the $\mathrm{Cr} / \mathrm{Cu}$ interface.

\subsection{Microstructure and Mechanical Properties of $\mathrm{Cu}-\mathrm{BCs}$}

Figure 6 shows the microstructure of $\mathrm{Cu}-\mathrm{Fe}-\mathrm{Gr}$ and $\mathrm{Cu}-\mathrm{Cr}-\mathrm{Gr}$ materials. $\mathrm{Fe}, \mathrm{Cr}$, and $\mathrm{Gr}$ were evenly distributed in the $\mathrm{Cu}$ matrix. Among them, the black bulky phases were granular graphite, which were used to reduce the vibration and stabilization braking. Light dark irregular phases in Figure 6a and white granular phases in Figure $6 \mathrm{~b}$ were Fe and $\mathrm{Cr}$ respectively, which were used for improving tribology performance and reducing wear resistance.
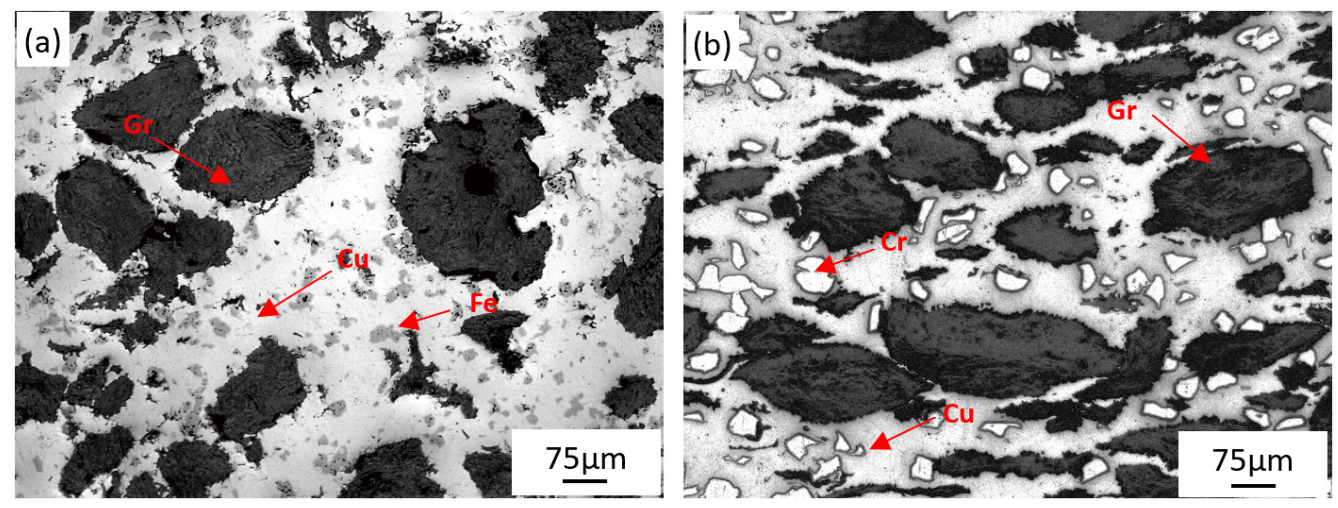

Figure 6. Microstructure of Cu-BCs: (a) Cu-Fe-Gr and (b) Cu-Cr-Gr. 
The Brinell hardness of $\mathrm{Cu}-\mathrm{BCs}$ is presented in Figure 7. Fe and $\mathrm{Cr}$ phases had a hardness of $\mathrm{HV}_{0.1} 109 \mathrm{~N} / \mu \mathrm{m}_{2}$ and $\mathrm{HV}_{0.1} 248 \mathrm{~N} / \mu \mathrm{m}^{2}$, respectively. Owing to the diffusion bonding interface formed between the friction component and matrix, the addition of a friction component can effectively improve the hardness of composites by means of particle strengthening. Between them, because of higher hardness, Cr showed a better particle strengthening effect than $\mathrm{Fe}$, though its interface strength is relatively lower. It can also be noticed that, owing to the low strength of the lubrication component, the addition of graphite led to an obvious decrease in the hardness of $\mathrm{Cu}-\mathrm{BCs}$.

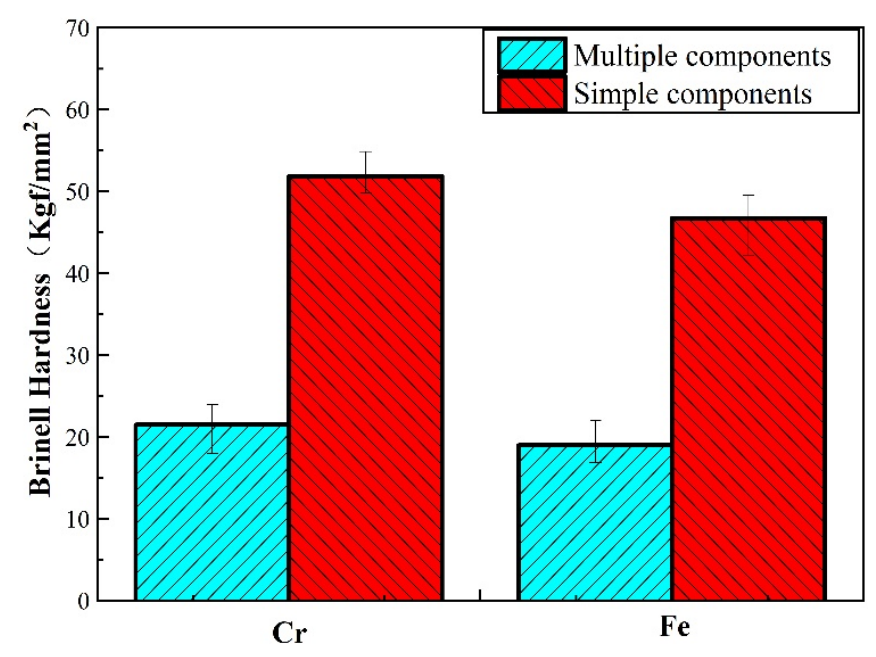

Figure 7. Brinell hardness of $\mathrm{Cu}-\mathrm{BCs}$.

\subsection{Micro-Friction Tests}

During the braking process, macro friction can be regarded as the accumulation of micro friction. Therefore, an analysis of the micro friction performance of $\mathrm{Fe}$ and $\mathrm{Cr}$ components and their interface was needed to better understand the macro-tribological behaviours of the friction materials.

\section{Tribological Properties of the $\mathrm{Fe}$ and $\mathrm{Cr}$ Phase and Its Interface}

Figure 8 presents the scratch grooves across the $\mathrm{Fe} / \mathrm{Cu}$ and $\mathrm{Cr} / \mathrm{Cu}$ interfaces under different levels of normal force. The widths of the grooves noticeably increased when the indenter slid from the friction component to the $\mathrm{Cu}$ matrix. However, the width increase of the $\mathrm{Fe}-\mathrm{Cu}$ composite was relatively small compared with that of the $\mathrm{Cr}-\mathrm{Cu}$ composite. When the normal force increased gradually, there was also significant growth in the widths of the grooves, especially for the copper matrix under normal force of $0.5 \mathrm{~N}$. The morphology of the groove in the interface bonding area is illustrated in detail on the right side of Figure 8. For Fe-Cu composites, distinct interface deformation occurred at the $\mathrm{Fe} / \mathrm{Cu}$ interface along the sliding direction under all test conditions. Notably, the $\mathrm{Fe} / \mathrm{Cu}$ interface still maintained good interface bonding after the scratch process. Compared with the $\mathrm{Fe} / \mathrm{Cu}$ interface, although the deformation degree of the $\mathrm{Cr} / \mathrm{Cu}$ interface was smaller, partially broken and local interfacial debonding began to occur when the normal force reached $0.5 \mathrm{~N}$. 

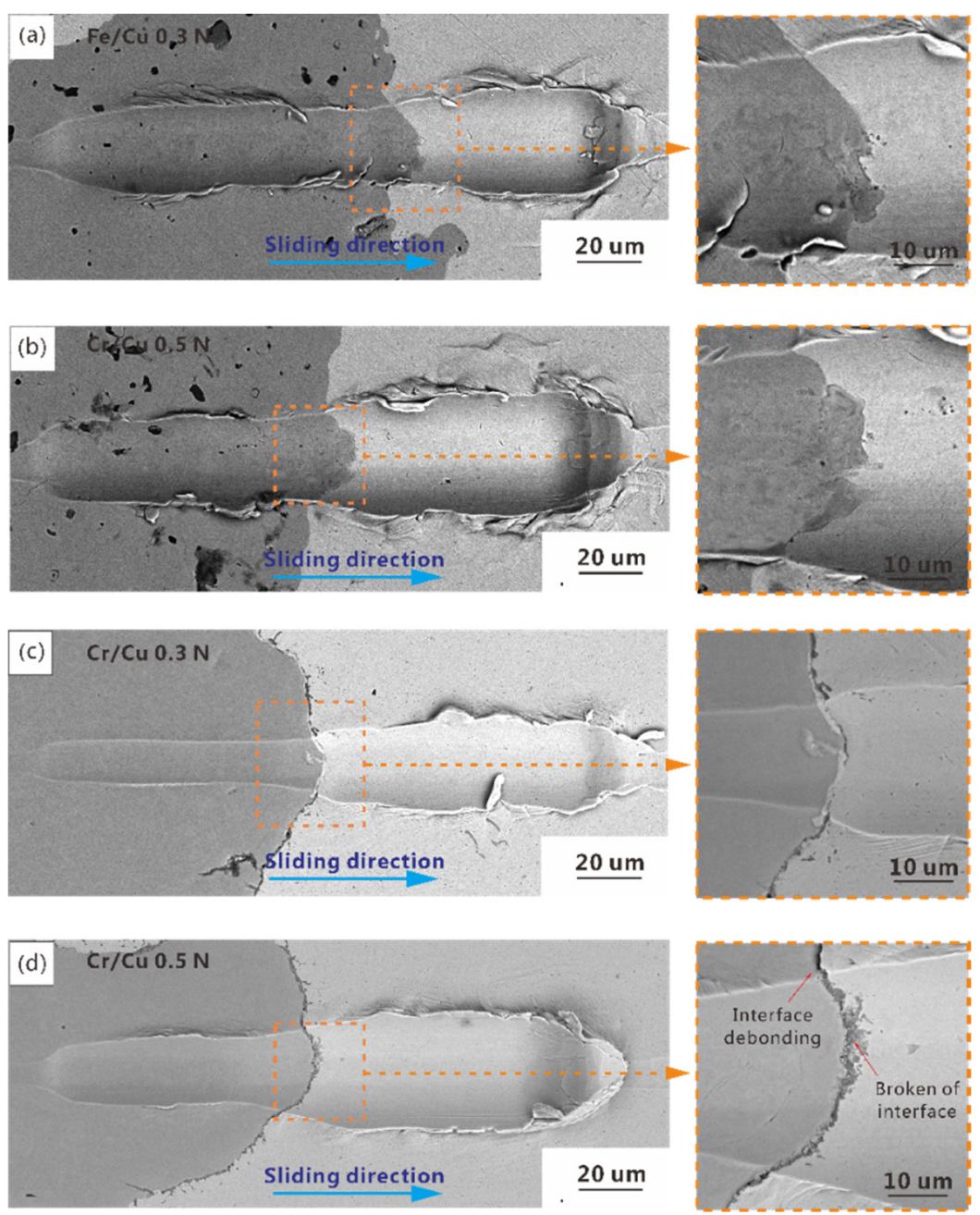

Figure 8. Scratch grooves of the $\mathrm{Fe} / \mathrm{Cu}$ interface and $\mathrm{Cr} / \mathrm{Cu}$ interface with different forces: (a) $0.3 \mathrm{~N}$ $\mathrm{Fe} / \mathrm{Cu}$ interface; (b) $0.5 \mathrm{~N} \mathrm{Fe} / \mathrm{Cu}$ interface; (c) $0.3 \mathrm{~N} \mathrm{Cr} / \mathrm{Cu}$ interface; and (d) $0.5 \mathrm{~N} \mathrm{Cr} / \mathrm{Cu}$ interface.

Figure 9 shows the COF curves with sliding distance under different levels of normal force. The value of COF was positively correlated with normal force. However, the different interface types showed completely different change tendencies in $\mathrm{COF}$. For $\mathrm{Fe}-\mathrm{Cu}$ composites, the COF increased slowly when the indenter slid across the $\mathrm{Fe} / \mathrm{Cu}$ interface, especially under a pressure of $0.5 \mathrm{~N}$. For $\mathrm{Cr}-\mathrm{Cu}$ composites, the $\mathrm{COF}$ first showed a decreasing tendency and then an increasing tendency. When the normal force reached $0.5 \mathrm{~N}$, the COF displayed a sharp decrease at the $\mathrm{Cr} / \mathrm{Fe}$ interface. Figure 10 exhibits the penetration depth (Pd) and $\mathrm{Rd}$ (residual depth) curves with sliding distance under different normal forces. Notably, the Pd and Rd curves show similar change patterns to the COF curves. However, the changes in the $\mathrm{Pd}$ and $\mathrm{Rd}$ curves showed a slight difference in the interface area. 

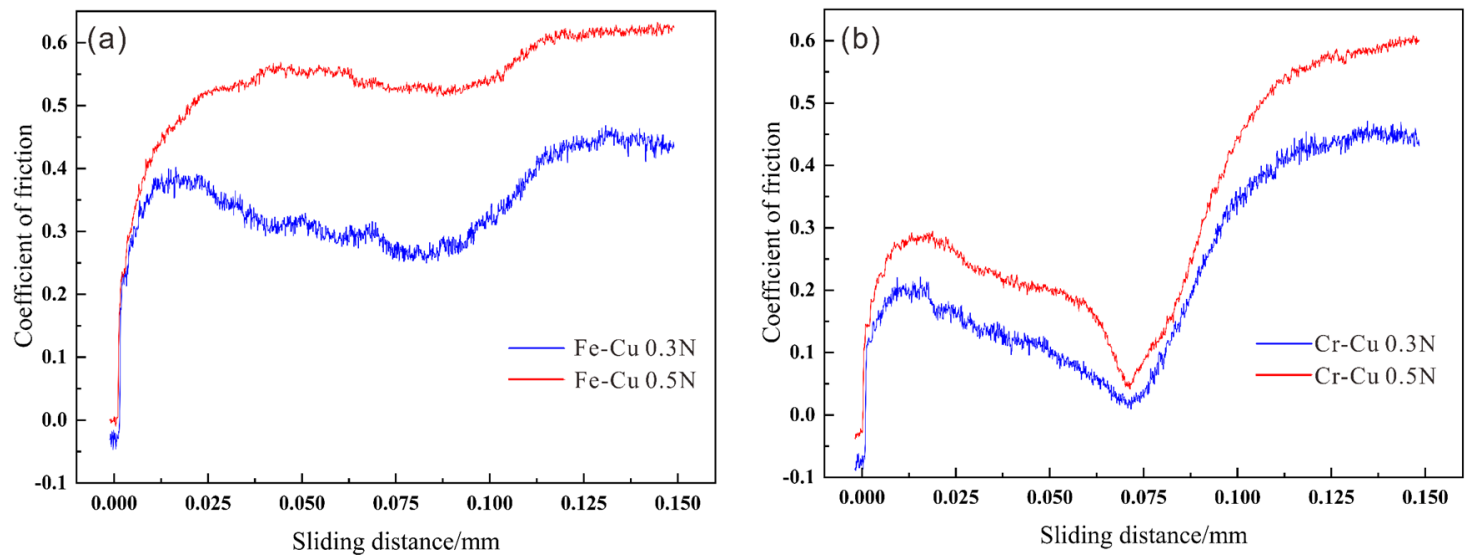

Figure 9. Curves of the coefficient of friction plotted versus the sliding distance in the $\mathrm{Cu} / \mathrm{Fe}$ and $\mathrm{Cr} / \mathrm{Cu}$ interface regions under different applied loads: (a) Fe/ $\mathrm{Cu}$ interface regions and (b) $\mathrm{Cu} / \mathrm{Cr}$ interface regions.
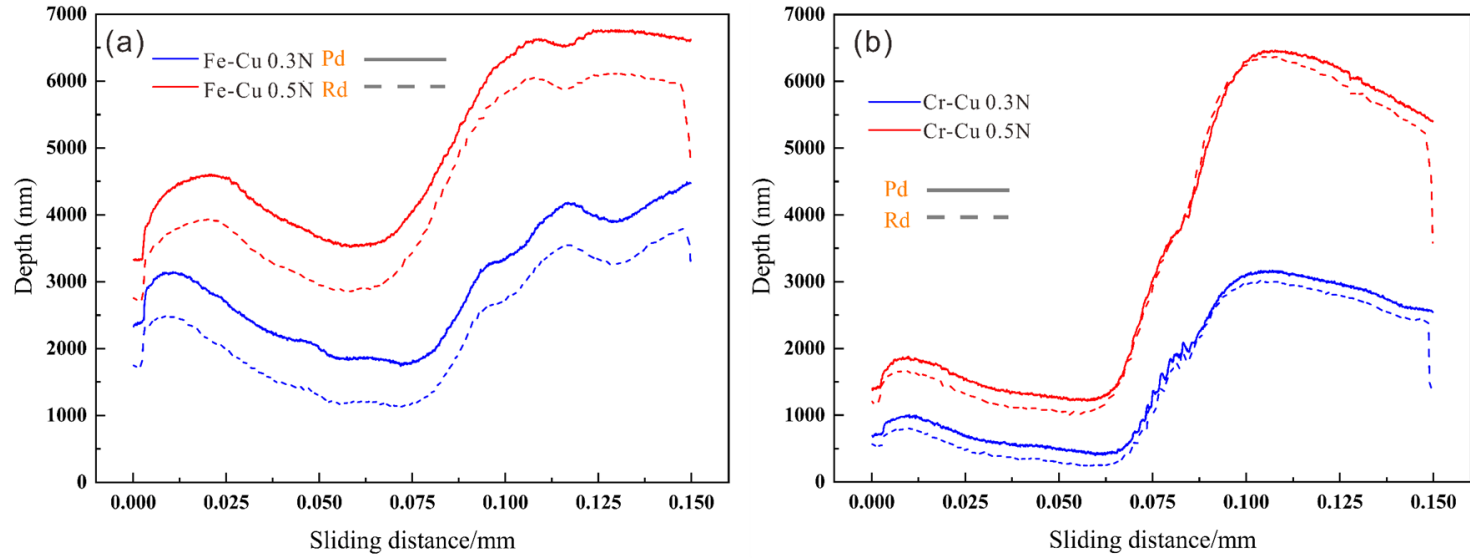

Figure 10. Curves for the $h_{r d}, h_{p d}$ of friction plotted against the sliding distance in the $\mathrm{Fe} / \mathrm{Cu}$ and $\mathrm{Cr} / \mathrm{Cu}$ interface regions under different forces: (a) $\mathrm{Cu} / \mathrm{Fe}$ interface regions and (b) $\mathrm{Cu} / \mathrm{Cr}$ interface regions.

Figure 11 displays a schematic of the micro-friction tests. According to the adhesive friction theory, the COF can be obtained as [25]

$$
\mu=\mu_{p}+\mu_{a}
$$

where $\mu_{p}$ is the COF of ploughing and $\mu_{a}$ is the COF of adhesion. Owing to the poor adhesive tendency between the indenter and $\mathrm{Cu}-\mathrm{BCs}, \mu_{p}$ plays a leading role during the sliding process. Moreover, for $\mu_{p}$, the values of Pd and Rd are close to each other, indicating that plastic deformation is the main deformation mechanism during the sliding process (elastic recovery is limited). Thus, the COF of ploughing can be given as [26-28]

$$
\mu_{p}=\frac{f_{p}}{N}=\frac{A_{p} H_{p}}{A_{s} H_{s}}
$$

where $A_{p}$ and $A_{s}$ are the projection areas of the contact region along the horizontal and vertical directions, respectively, as shown in Figure $11 . H_{p}$ and $H_{s}$ are the plough hardness and scratch hardness of the friction components or $\mathrm{Cu}$ matrix, which are defined as the deformation resistance per unit projected area along the horizontal and vertical direction, 
respectively. Thanks to the homogeneity of the friction components and the matrix, $H_{p}$ and $H_{s}$ can be regarded as identical, which means that the COF of ploughing can be calculated as

$$
\mu_{p}=\frac{A_{p}}{A_{s}}=\frac{R^{2} \cos ^{-1}\left(1-\frac{h_{\mathrm{Pd}}}{R}\right)-\left(R-h_{\mathrm{Pd}}\right) \sqrt{2 R h_{\mathrm{Pd}}-h_{\mathrm{Pd}}{ }^{2}}}{\pi\left(R h_{\mathrm{Pd}}-\frac{1}{2} h_{\mathrm{Pd}}{ }^{2}\right)}
$$

where $R$ is the indenter radius, $h_{P d}$ is the penetration depth, and $r$ is the radius of the vertical projection semicircle. Equation (6) shows that the COF increased with $h_{P d}$, which explains why COF and $h_{p d}$ shared similar patterns of change and indicates that the COF is positively correlated with normal force, but negatively correlated with hardness.

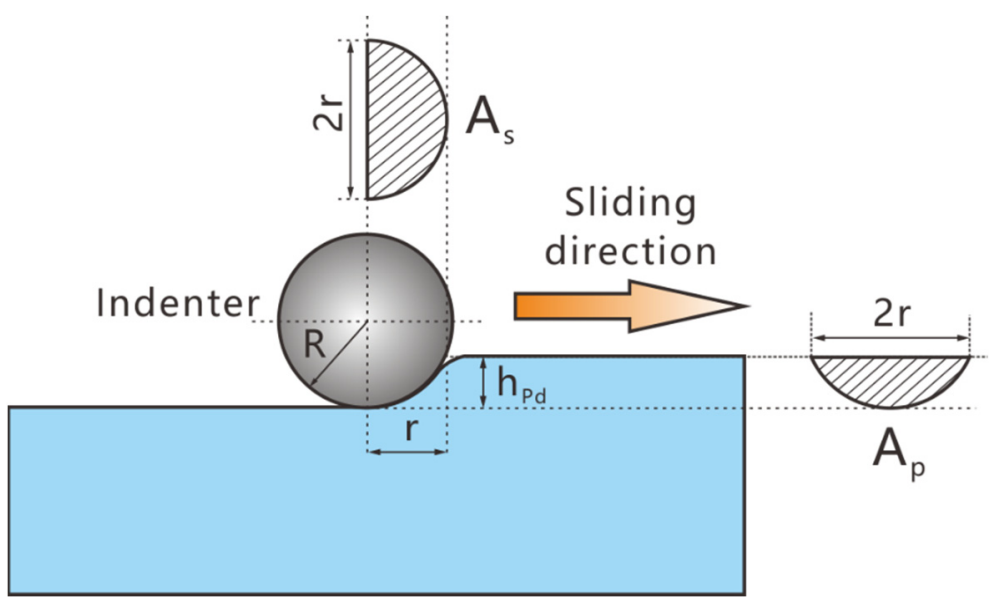

Figure 11. The schematic of indenter scratching on $\mathrm{Cu}-\mathrm{BCs}$.

The COF of adhesion can be calculated as

$$
\mu_{a}=\frac{k \tau_{s} A_{s}}{H_{s} A_{s}}=\frac{k \tau_{s}}{H_{s}}
$$

where $k$ is the ratio of adhesive area to contact area and $\tau_{s}$ is the shear strength. According to Equation (7), the adhesion component of COF is almost constant. The change of COF mainly was mainly caused by the variation of the plough component of COF. As shown in Equation (6), a sudden change in hardness on both sides of the interface leads to a rapid change in the COF and $h_{p d}$ during the micro-friction tests. A low scratching normal pressure and a relatively high hardness usually indicate a deeper $h_{P d}$ and higher COF; therefore, the values of $h_{P d}$ and COF increase with normal pressure and present a rapid increase when sliding from hard friction components to the soft matrix. Nevertheless, because of the obvious deformation of the $\mathrm{Fe} / \mathrm{Cu}$ interface along the sliding direction owing to its stronger bonding strength and better ductility, the changing trend of hardness at the interface slowed, causing a reduction in the rate of growth of $h_{p d}$ and COF in the interface area. The phenomenon that COF showed a decrease prior to an increase in the $\mathrm{Cr} / \mathrm{Cu}$ interface under a normal force of $0.5 \mathrm{~N}$ was caused by the debonding of the $\mathrm{Cr} / \mathrm{Cu}$ interface, which meant that $\mathrm{Cr} / \mathrm{Cu}$ interface was no longer able to provide sufficient plough resistance during scratching. The micro-friction test results confirmed that the $\mathrm{Fe} / \mathrm{Cu}$ interface has a higher strength than that of the $\mathrm{Cr} / \mathrm{Cu}$ interface.

\subsection{Macro-Friction Tests}

\subsubsection{Wear Mechanism}

The friction and wear performance of $\mathrm{Cu}-\mathrm{BC}$ s containing $\mathrm{Fe}$ and $\mathrm{Cr}$ (samples $3 \#$ and 4\#) was measured by a MM-3000 friction tester. Wear debris, subsurface (cross-section), and the worn surface were analysed after the macro-friction tests. 
The evolution of the worn surfaces of $\mathrm{Cu}-\mathrm{BC}$ s under different BEPUAs is shown in Figure 12. The worn surface morphology of the $\mathrm{Cu}-\mathrm{BC}$ s changed from a flat surface to a rugged and scarred surface with an increase in BEPUA.
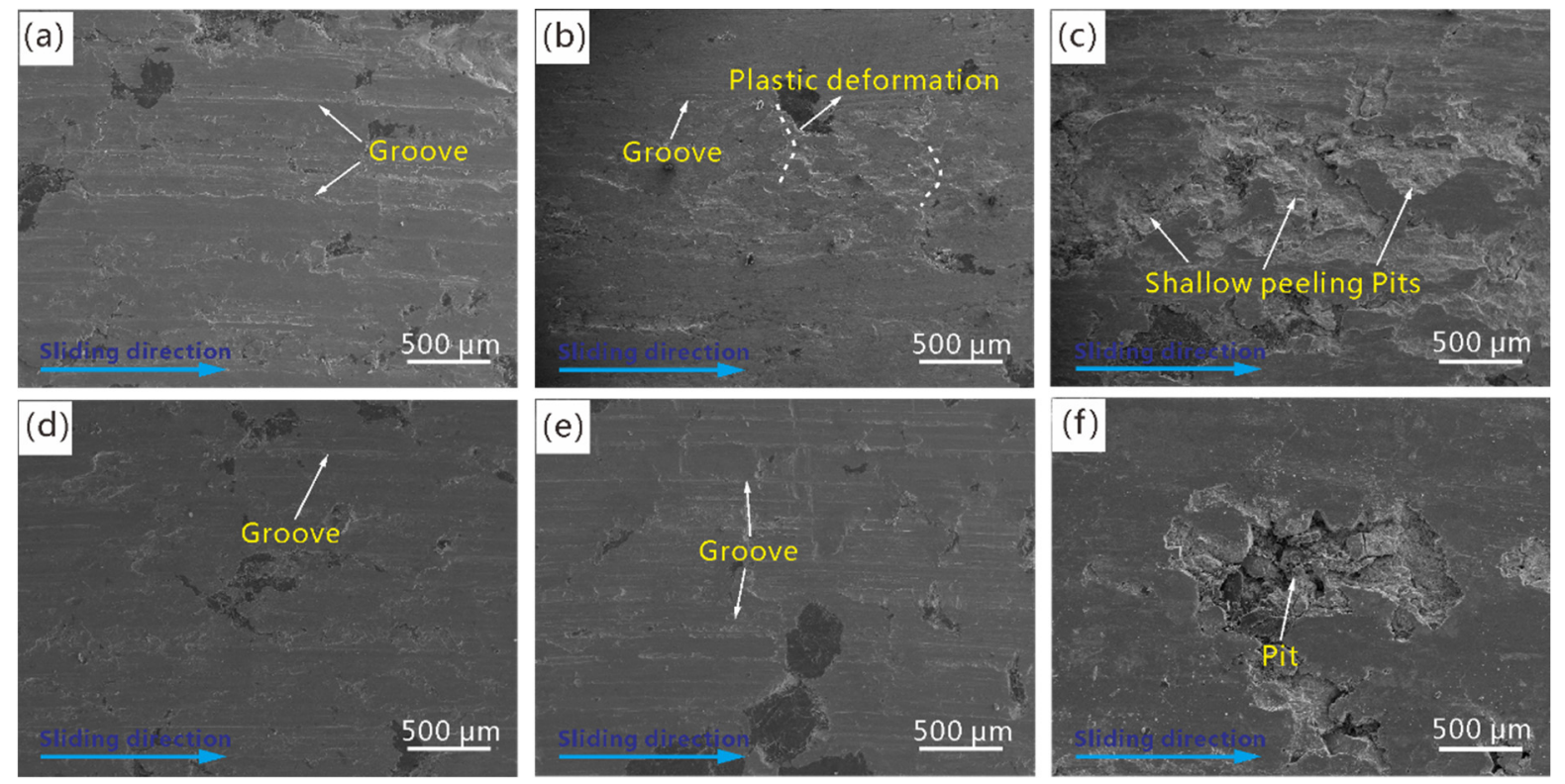

Figure 12. The worn surfaces of $\mathrm{Cu}-\mathrm{BC}$ s containing Fe and $\mathrm{Cr}$ tested under different BEPUAs: (a) Fe low-BEPUA; (b) Fe medium-BEPUA; (c) Fe high-BEPUA; (d) Cr low-BEPUA; (e) Cr medium-BEPUA; and (f) Cr high-BEPUA.

Under a low BEPUA, regardless of the types of friction components contained in the $\mathrm{Cu}-\mathrm{BCs}$, the grooves parallel to the sliding direction were the main wear morphology. It is noted that the number and width of grooves on the worn surface of $\mathrm{Cu}-\mathrm{BC}$ containing $\mathrm{Fe}$ is higher than that of $\mathrm{Cu}-\mathrm{BC}$ with $\mathrm{Cr}$. As the BEPUAs increased, the wear morphology of tested samples started to form obvious differences. For $\mathrm{Cu}-\mathrm{BC}$ containing $\mathrm{Cr}$, the density of grooves on the worn surface showed an increase tendency with BEPUA. However, for $\mathrm{Cu}-\mathrm{BC}$ containing $\mathrm{Fe}$, a wave-like wear morphology began to generate on the worn surface, which indicated strong local plastic deformation after the braking process, as shown in Figure 12b. By continuing to increase the BEPUA to a high level, the difference in the worn surface continued to increase for different tested samples. The worn surface of $\mathrm{Cu}-\mathrm{BC}$ with Fe featured shallow pits with a high area ratio and a small number of grooves, as shown in Figure 12c. In addition, some undischarged fine particles can be found inside these pits. Nevertheless, the worn surface of $\mathrm{Cu}-\mathrm{BC}$ with $\mathrm{Cr}$ exhibited lots of deep pits, and bits of friction components are exposed at the bottom of these pits, as shown in Figure 12f.

Figure 13 shows the typical subsurface structures and wear debris of $\mathrm{Cu}-\mathrm{BC}$ s containing different friction components under different BEPUAs. Under low BEPUA conditions, there was no obvious subsurface structure formed on the worn surfaces of the $\mathrm{Cu}-\mathrm{BCs}$ containing $\mathrm{Fe}$ or $\mathrm{Cr}$, as shown in Figure 13a,b. A continuous plastic deformation layer (PDL) with a thickness of 10-20 $\mu \mathrm{m}$ occurred on the worn surfaces of the $\mathrm{Cu}-\mathrm{BCs}$ containing $\mathrm{Fe}$, with an increase of BEPUA. However, limited plastic deformation of the $\mathrm{Cu}-\mathrm{BC}$ s containing $\mathrm{Cr}$ led to the formation of thin incomplete PDLs, as shown in Figure 13e.

When the BEPUA increased to a higher level, the subsurface evolution pattern showed a more diverse changing trend for two kinds of $\mathrm{Cu}-\mathrm{BCs}$. For instance, as shown in Figure 13c, the $\mathrm{Cu}-\mathrm{BCs}$ containing Fe showed a distinct three-layer structure, which consisted of a mechanical mixed layer (MML) formed by the accumulation of small particles of wear debris and second sintering under the influence of friction heat, as well as Fe-rich PDL and an undeformed matrix from top to bottom. However, the $\mathrm{Cu}-\mathrm{BC}$ s containing $\mathrm{Cr}$ still did not form a typical subsurface structure, except for the generation of cracks beneath the surface of materials, as indicated in Figure 13f. 

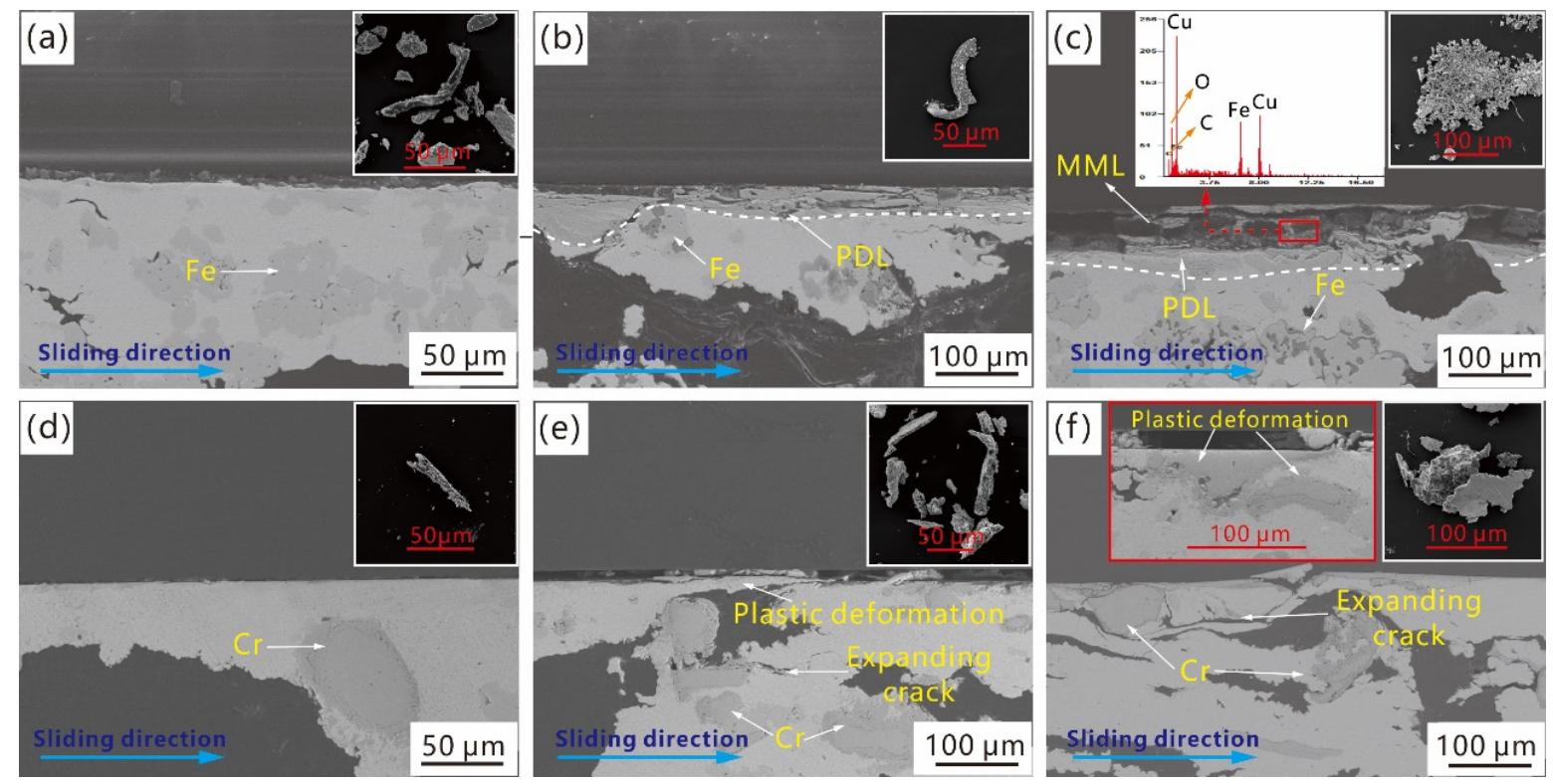

Figure 13. Subsurface and wear debris of $\mathrm{Cu}-\mathrm{BC}$ s containing $\mathrm{Fe}$ and $\mathrm{Cr}$ tested under different BEPUA conditions: (a) Fe low-BEPUA; (b) Fe medium-BEPUA; (c) Fe high-BEPUA; (d) Cr low-BEPUA; (e) Cr medium-BEPUA; (f) Cr high-BEPUA.

Under low and medium BEPUAs, the stripe-like shape was the main characteristic of wear debris among the $\mathrm{Cu}-\mathrm{BCs}$. The shape of the wear debris transformed from stripe-like to thin flake-like shapes on $\mathrm{Cu}-\mathrm{BC}$ s containing Fe and to thick flake-like shapes for $\mathrm{Cu}-\mathrm{BC}$ s containing $\mathrm{Cr}$ under high BEPUAs, as shown in Figure 13.

The mechanical properties of the friction components and interface bonding strength between the friction components and matrix were attributed to the difference in the evolutionary patterns of worn surfaces or subsurfaces between two kinds of $\mathrm{Cu}-\mathrm{BC}$. Under low and medium BEPUAs conditions, owing to a better particle strengthening effect of $\mathrm{Cr}$ with higher hardness, $\mathrm{Cu}-\mathrm{BC}$ s containing $\mathrm{Cr}$ showed a high resistance to plastic deformation. Therefore, plastic deformation had more difficulty developing on the worn surfaces of the $\mathrm{Cu}-\mathrm{BC}$ s containing $\mathrm{Cr}$ compared with that of $\mathrm{Cu}-\mathrm{BC}$ s containing Fe. The result, depth, and quantity of grooves on worn surface of $\mathrm{Cu}-\mathrm{BCs}$ containing $\mathrm{Cr}$ were smaller than the other. In this condition, the plough was the main wear mechanism for $\mathrm{Cu}-\mathrm{BC}$ s regardless of what friction component composites contained.

Under high BEPUA conditions, because of the poor wear resistance of the Cu matrix, the quality loss of the $\mathrm{Cu}$ matrix was much larger than that of Fe. With the surface of the $\mathrm{Cu}$ matrix being worn out, the exposed Fe phases started to spread along the sliding direction under repeated friction shear stress, leading to the formation of an Fe-rich PDL with high strength. Furthermore, under the premise of the stable existence of PDL, as the high-energy braking continued, under periodic high-frequency shear stress and compressive stress, the fine wear debris that remained on the worn surface tended to accumulate and connect to each other due to second sintering caused by friction heat, leading to the occurrence of MML. The wear of $\mathrm{Cu}-\mathrm{BC}$ s containing Fe was caused by the peeling of MML due to the expansion of cracks along the rubbing direction, which were nucleated in the bonding defects and oxidation defects of MML. Therefore, the change in the wear mechanism from ploughing to MML destruction induced delamination, as shown on the left part in Figure 14

Thanks to the effective particle strengthening of $\mathrm{Cr}$, even under high BEPUA, the plastic deformation of the worn surface was not obvious for $\mathrm{Cu}-\mathrm{BCs}$ containing $\mathrm{Cr}$. However, the defect interface layer on $\mathrm{Cr} / \mathrm{Cu}$ interface easily developed into the sources of cracks, causing the nucleation and propagation of cracks. As shown on the right part in Figure 14, when the cracks propagated to the surface of materials along the rubbing direction, the peeling of the copper matrix led to the wear of $\mathrm{Cu}-\mathrm{BC}$ s containing $\mathrm{Cr}$, resulting in the formation 
of thick flake-like wear debris. The wear mechanism transformed from ploughing- to matrix-peeling-induced delamination, as shown on the right side of Figure 13.

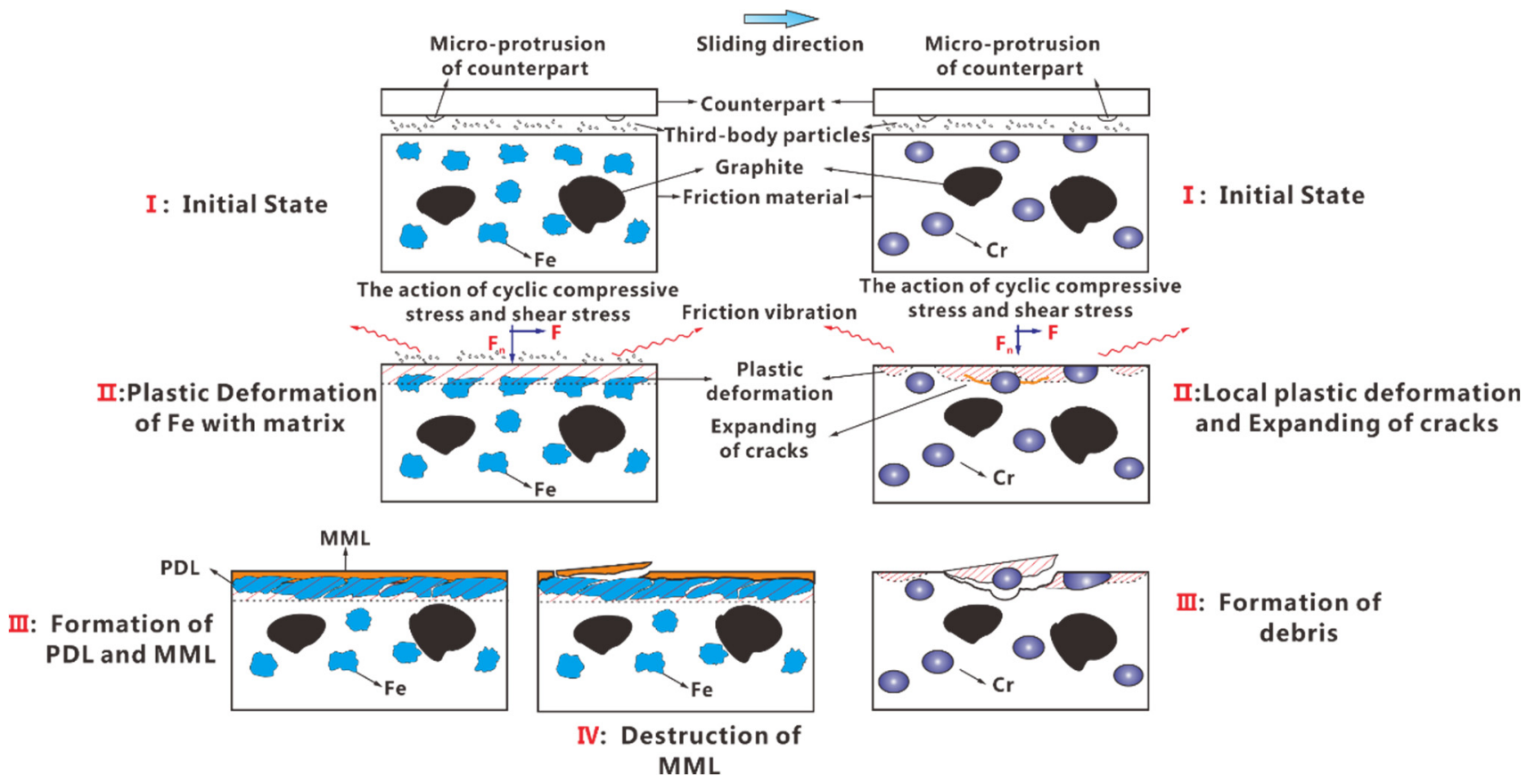

Figure 14. Evolution of the wear mechanism for $\mathrm{Cu}-\mathrm{BC}$ s containing Fe and $\mathrm{Cr}$ under high BEPUA.

\subsubsection{Friction and Wear Behaviour}

The time-dependence curves of instantaneous COF under different BEPUAs are displayed in Figure 15. Typical saddle-like braking curves were visibly formed under nearly all test conditions. Furthermore, with an increase in BEPUA, the whole braking time showed a growth trend, but the COF displayed the opposite change tendency. Furthermore, $\mathrm{Cu}-\mathrm{BC}$ s containing Fe showed more stable $\mathrm{COF}$ curves than those containing $\mathrm{Cr}$ under high BEPUA.

The formation of saddle-like braking curves is attributed to the change in friction surface morphology between the friction material and its counterpart during braking. The sudden braking shock was the main reason for the high COF in the early stages of braking. Then, with the generation of soft debris from the copper matrix or graphite at the friction interface, the instantaneous COF began to gradually decrease. During the end stage of braking, owing to a reduction in the amount of soft debris and the change from dynamic friction to static friction, the instantaneous COF increased again, eventually giving rise to the up-tail phenomenon of COF curves.

The differences in the braking performance of $\mathrm{Cu}-\mathrm{BC}$ s containing different friction components under a high BEPUA resulted from the friction component characteristics and subsurface structural diversity. Fe's contribution to the formation of oxidized MML on the worn surface, which featured relatively high hardness and strong heat resistance, helped to smooth the braking process. However, no obvious subsurface structure was formed on the worn surfaces of $\mathrm{Cu}-\mathrm{BC}$ s containing $\mathrm{Cr}$. The distinct decrease of $\mathrm{COF}$ in the middle stage of braking was mainly caused by a softening of the copper matrix due to friction heat accumulation. This explains why the $\mathrm{COF}$ of $\mathrm{Cu}-\mathrm{BC}$ s containing Fe showed better stability. 

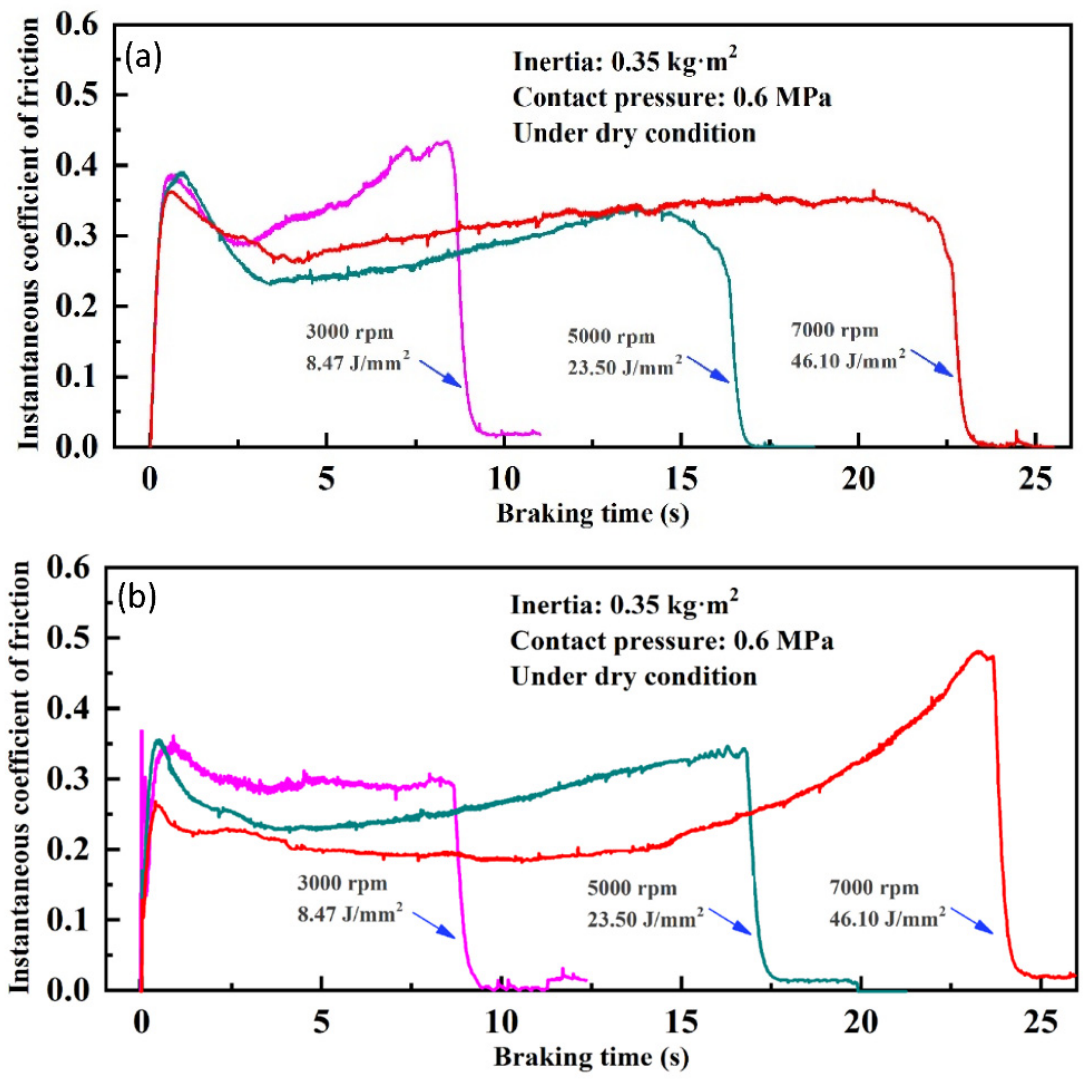

Figure 15. The instantaneous coefficients of friction of $\mathrm{Cu}-\mathrm{BC}$ s containing $\mathrm{Fe}(\mathbf{a})$ and $\mathrm{Cr}(\mathbf{b})$.

Figure 16 illustrates the variations in the mean COF over 10 cycles of braking for $\mathrm{Cu}-\mathrm{BC}$ s containing $\mathrm{Fe}$ and $\mathrm{Cr}$ under different BEPUAs. The overall trend of COF showed a decrease with an increase in BEPUA for $\mathrm{Cu}-\mathrm{BC}$ s containing two kinds of friction components. Between them, $\mathrm{Cu}-\mathrm{BC}$ s containing Fe always showed a higher COF compared with those containing $\mathrm{Cr}$ under nearly all test conditions. In addition, under a high BEPUA, the fluctuation of $\mathrm{COF}$ in the $\mathrm{Cu}-\mathrm{BC}$ s containing Fe was also relatively smaller than that of the $\mathrm{Cu}-\mathrm{BC}$ s containing $\mathrm{Cr}$, as shown in Figure 16 .
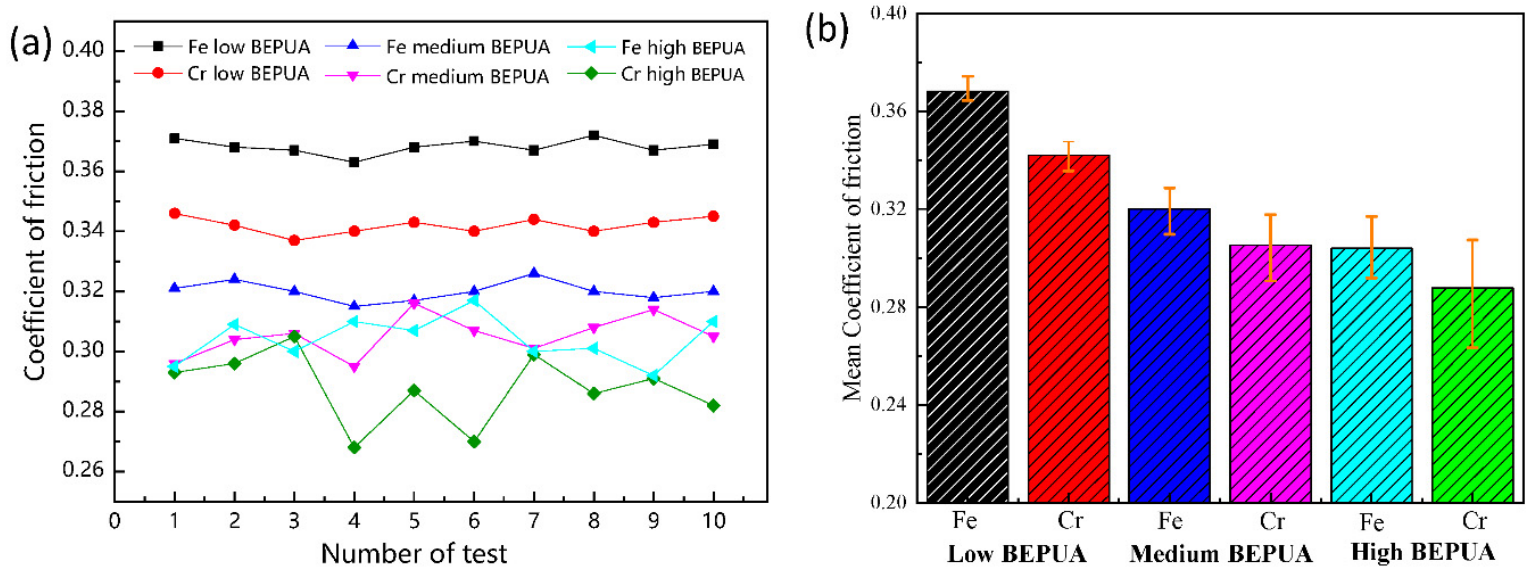

Figure 16. Variations in the coefficient of friction with the number of tests (a) and the mean coefficient of friction (b) of $\mathrm{Cu}-\mathrm{BC}$ s containing $\mathrm{Fe}$ and $\mathrm{Cr}$.

Well strength of diffusion bonding is beneficial to the function developing of Fe and Cr. Before the friction layer formed, the friction performance mainly depended on the intrinsic friction properties of each elements and their distribution area ratios. Under a 
low BEPUA, The absorption of braking energy by the deformation of worn surface was the main source of friction resistance. When the materials contain multiple components, assume that the normal pressure acting on each component is uniform, and the COF can be expressed as [28]

$$
\mu=\sum_{i=1}^{N}\left(\mu_{i p}+\mu_{i a}\right) \cdot \alpha_{i}
$$

where $\alpha_{i}$ is the covering area of each phase, $\mu_{i p}$ is the ploughing COF of single component, and $\mu_{i a}$ is the adhesion COF of single component.

Because $\mathrm{Fe}$ and $\mathrm{Cr}$ had the same volume content, the difference in friction performance was related to the frictional properties of $\mathrm{Fe}$ and $\mathrm{Cr}$ itself. According to the results of the micro-friction tests, $h_{p d}$ on the Fe particles was deeper under the same pressure, which resulted in intensive plastic deformation. This result indicates that the $\mu_{i p}$ of Fe was much higher than that of $\mathrm{Cr}$. Moreover, the adhesion tendency of Fe to alloy counterpart is much higher than that of $\mathrm{Cr}$, which caused that the $\mu_{i a}$ of Fe was higher than that of $\mathrm{Cr}$ as well. Hence, $\mathrm{Cu}$-BCs containing Fe showed a higher COF, as shown in Figure 16.

With an increase in BEPUA, the surface temperature of the materials gradually raised, and the vibration intensified. Under these circumstances, the matrix softened, and more braking energy transformed into impact energy, leading to a decrease in the COF. Therefore, under a medium BEPUA, the COFs in the two kinds of $\mathrm{Cu}-\mathrm{BCs}$ decreased observably. With a further increase in BEPUAs, the formed friction layer replaced the original friction surface, the tribology behavior of material is controlled by the structure and properties of friction layer. According to the fixed adhesion theory [29],

$$
\mu=\frac{\tau_{f}}{\sigma_{s}}
$$

where $\tau_{f}$ is the shear strength of the friction layer. Because the oxidized MML shows better mechanical properties than the exposed matrix, the composites containing Fe had a higher $\mathrm{COF}$ than that of the composites containing $\mathrm{Cr}$. The vibration in the COF of $\mathrm{Cu}-\mathrm{BCs}$ with $\mathrm{Cr}$ was related to the worn mechanism under a high BEPUA. The intense variations could be attributed to the participation of large size hard wear debris in braking process as a third body, due to peeling of $\mathrm{Cr}$ with flake-like wear debris.

Figure 17 shows the wear rates of the $\mathrm{Cu}-\mathrm{BC}$ s containing $\mathrm{Fe}$ and $\mathrm{Cr}$ under different BEPUAs. The wear rate increased with an increase of BEPUA. Under low and medium BEPUA values, the $\mathrm{Cu}-\mathrm{BC}$ s containing Fe exhibited a higher wear rate than those containing $\mathrm{Cr}$. Moreover, the wear rate increased rapidly for $\mathrm{Cu}-\mathrm{BC}$ s containing $\mathrm{Cr}$ with BEPUA. However, when BEPUA reached a high level, a sharp increase was observed in the wear rates of the $\mathrm{Cu}-\mathrm{BCs}$ with $\mathrm{Cr}$, which began to exceed the wear rates of $\mathrm{Cu}-\mathrm{BC}$ s with $\mathrm{Fe}$. The wear rates of the counterparts followed a similar change pattern. Notably, the counterparts of $\mathrm{Cu}-\mathrm{BC}$ s with $\mathrm{Cr}$ always showed a higher wear rate, as presented in Figure $17 \mathrm{~b}$.

The friction components were not destroyed under low and medium BEPUAs. In this situation, the friction components with the highest hardness were able to significantly improve the wear resistance of $\mathrm{Cu}-\mathrm{BCs}$. Consequently, $\mathrm{Cu}-\mathrm{BC}$ s with $\mathrm{Cr}$ showed a lower wear rate under low and medium BEPUAs. However, under a high BEPUA, wear resistance was dependent on the subsurface structure. The $\mathrm{Fe} / \mathrm{Cu}$ interface promoted the formation of MML with high hardness, thereby controlling the excessive wear of the $\mathrm{Cu}-\mathrm{BC}$. No protective friction layer was formed on the worn surfaces of the $\mathrm{Cu}-\mathrm{BCs}$ containing $\mathrm{Cr}$ under a high BEPUA, resulting in severe delamination wear.

The wear rates of the counterparts mainly related to the hardness of the friction components and the wear mechanism of the friction system. Under all tested conditions, $\mathrm{Cr}$ always showed stronger destruction capabilities than the tested counterparts. Therefore, the wear rates of the counterparts for the $\mathrm{Cu}-\mathrm{BCs}$ containing $\mathrm{Cr}$ were higher, especially under a high BEPUA. The wear of the counterparts was further aggravated by delamination and the increase in tertiary bodies. 

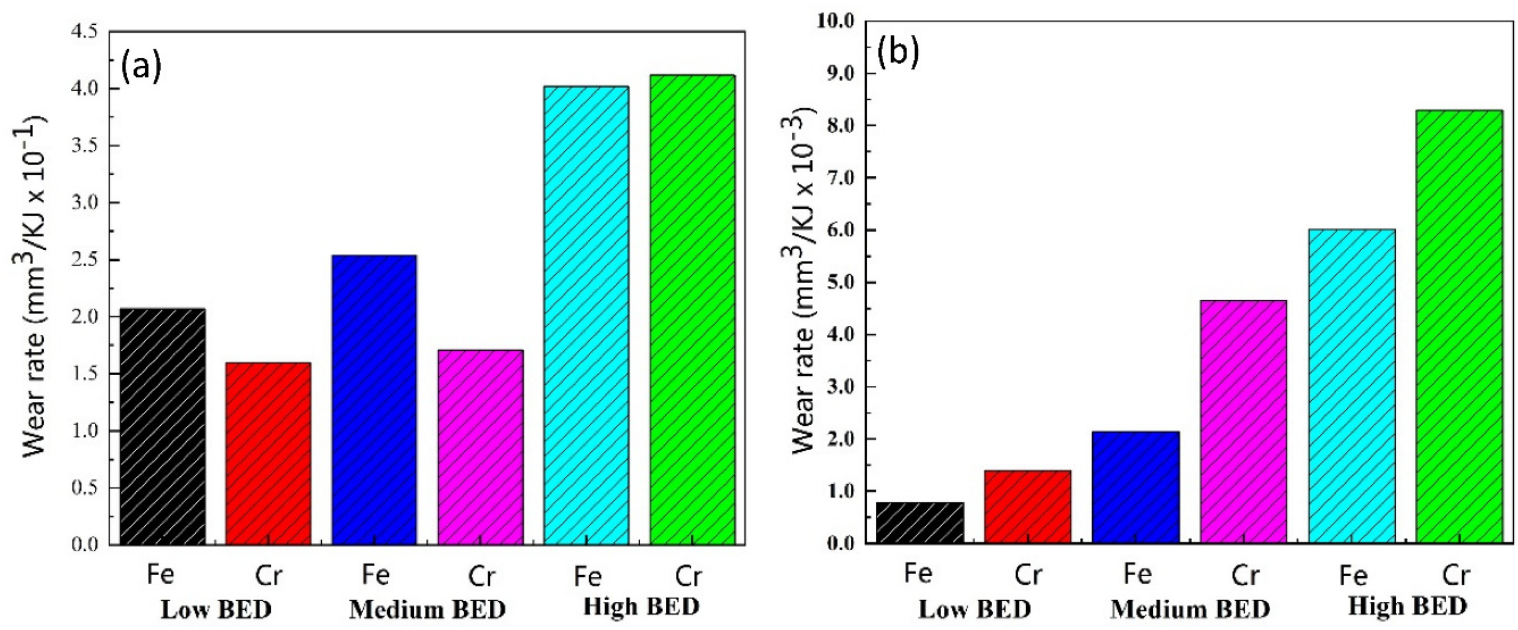

Figure 17. The wear rate of $\mathrm{Cu}-\mathrm{BCs}$ and its counterpart: (a) wear rate of $\mathrm{Cu}-\mathrm{BC}$ s and (b) wear rate of counterpart.

\section{Conclusions}

The following conclusions of this research can be drawn:

(1) A diffusion bonding interface was formed between Fe and the copper matrix, as well as between $\mathrm{Cr}$ and the copper matrix. Owing to the formation of the defect bonding layer, the $\mathrm{Cr} / \mathrm{Cu}$ interface exhibited a lower bonding strength compared with that of the $\mathrm{Fe} / \mathrm{Cu}$ interface. Therefore, Fe presents a better particle strengthening than $\mathrm{Cr}$, which enhanced the strength of $\mathrm{Cu}-\mathrm{BC}$ more effectively.

(2) The $\mathrm{COF}$ of the $\mathrm{Fe} / \mathrm{Cu}$ interface showed a slow growth trend owing to interface deformation. However, the $\mathrm{COF}$ of the $\mathrm{Cr} / \mathrm{Cu}$ interface first indicated a decrease followed by a sharp increase in the interface area owing to local interface debonding, especially at a pressure of $0.5 \mathrm{~N}$. Compared with $\mathrm{Cr}$, Fe can reduced the rapidly variation of the $\mathrm{COF}$ on interface bonding area during the micro friction test.

(3) Fe is conducive to the improvement of $\mathrm{COF}$, the $\mathrm{Cu}-\mathrm{BC}$ s containing Fe showed higher $\mathrm{COF}$ values than that of $\mathrm{Cu}-\mathrm{BC}$ s with $\mathrm{Cr}$ under all test conditions owing to its higher $\mathrm{COF}$ component. $\mathrm{Cr}$ is beneficial to an improvement of wear resistance because of its higher hardness, The $\mathrm{Cu}-\mathrm{BC}$ s containing $\mathrm{Cr}$ presented a lower wear rate than that of $\mathrm{Cu}-\mathrm{BC}$ containing Fe.

(4) Under low and medium BEPUAs, ploughing was the main wear mechanism for all tested composites. However, under high BEPUAs, Fe promoted the formation of MML, meaning that the delamination induced by destruction of MML became the main wear mechanism. However, the addition of $\mathrm{Cr}$ increased the quantity of interface defects in $\mathrm{Cu}-\mathrm{BCs}$, promoting the nucleation and propagation of cracks in composites during braking, meaning that the delamination induced by peeling of matrix near friction surface became the main wear mechanism.

Author Contributions: Conceptualization, H.Z., P.Y.; methodology, H.Z., Z.Z.; validation, T.G., Y.L.; formal analysis, L.Z., Y.X., M.D., Y.L.; investigation, Z.Z., H.Z., K.F.; resources, P.Y.; data curation, L.Z., Z.Z. and M.D.; writing-original draft preparation, Z.Z., H.Z.; writing-review and editing, P.Y., Y.X., K.F., H.Z.; visualization, H.Z. and Z.Z.; supervision, P.Y.; project administration, Z.Z.; funding acquisition, P.Y. All authors have read and agreed to the published version of the manuscript.

Funding: This work was supported by the National Nature Science Foundation of China [No: 51475476, No: 51805445].

Conflicts of Interest: The authors declare no conflict of interest. 


\section{References}

1. Zhou, H.; Yao, P.; Gong, T.; Xiao, Y.; Zhang, Z.; Zhao, L.; Fan, K.; Deng, M. Effects of $\mathrm{ZrO}_{2}$ crystal structure on the tribological properties of copper metal matrix composites. Tribol. Int. 2019, 138, 380-391. [CrossRef]

2. Barani, Z.; Mohammadzadeh, A.; Geremew, A.; Huang, C.Y.; Coleman, D.; Mangolini, L.; Kargar, F.; Balandin, A.A. Thermal Properties of the Binary-Filler Hybrid Composites with Graphene and Copper Nanoparticles. Adv. Funct. Mater. 2020, $30,1-25$. [CrossRef]

3. Hannula, P.M.; Peltonen, A.; Aromaa, J.; Janas, D.; Lundström, M.; Wilson, B.P.; Koziol, K.; Forsén, O. Carbon nanotube-copper composites by electrodeposition on carbon nanotube fibers. Carbon N. Y. 2016, 107, 281-287. [CrossRef]

4. Kim, W.J.; Lee, T.J.; Han, S.H. Multi-layer graphene/copper composites: Preparation using high-ratio differential speed rolling, microstructure and mechanical properties. Carbon N. Y. 2014, 69, 55-65. [CrossRef]

5. Chen, F.; Li, Z.; Zou, L.F.; Ma, W.J.; Li, J.W.; Chen, Z.; Niu, Z.B.; Liu, P.F.; Xiao, P. Tribological behavior and mechanism of h-BN modified copper metal matrix composites paired with C/C-SiC. Tribol. Int. 2021, 153, 106561. [CrossRef]

6. Wang, P.; Yue, W.; Lu, Z.; Zhang, G.; Zhu, L. Friction and wear properties of $\mathrm{MoS}_{2}$-based coatings sliding against $\mathrm{Cu}$ and $\mathrm{Al}$ under electric current. Tribol. Int. 2018, 127, 379-388. [CrossRef]

7. Xiong, X.; Chen, J.; Yao, P.; Li, S.; Huang, B. Friction and wear behaviors and mechanisms of $\mathrm{Fe}$ and $\mathrm{SiO}_{2}$ in $\mathrm{Cu}-\mathrm{based} \mathrm{P} / \mathrm{M}$ friction materials. Wear 2007, 262, 1182-1186. [CrossRef]

8. Xiao, Y.; Zhang, Z.; Yao, P.; Fan, K.; Zhou, H.; Gong, T.; Zhao, L.; Deng, M. Mechanical and tribological behaviors of copper metal matrix composites for brake pads used in high-speed trains. Tribol. Int. 2018, 119, 585-592. [CrossRef]

9. Xiao, Y.; Yao, P.; Zhou, H.; Zhang, Z.; Gong, T.; Zhao, L.; Zuo, X.; Deng, M.; Jin, Z. Friction and wear behavior of copper matrix composite for spacecraft rendezvous and docking under different conditions. Wear 2014, 320, 127-134. [CrossRef]

10. Peng, T.; Yan, Q.; Li, G.; Zhang, X.; Wen, Z.; Jin, X. The Braking Behaviors of Cu-Based Metallic Brake Pad for High-Speed Train Under Different Initial Braking Speed. Tribol. Lett. 2017, 65, 1-13. [CrossRef]

11. Peng, T.; Yan, Q.; Li, G.; Zhang, X. The Influence of Cu/Fe Ratio on the Tribological Behavior of Brake Friction Materials. Tribol. Lett. 2018, 66, 1-12. [CrossRef]

12. Zhang, P.; Zhang, L.; Fu, K.; Cao, J.; Shijia, C.; Qu, X. Effects of different forms of Fe powder additives on the simulated braking performance of $\mathrm{Cu}$-based friction materials for high-speed railway trains. Wear 2018, 414, 317-326. [CrossRef]

13. Komvopoulos, K.; Li, H. The Effect of Tribofilm Formation and Humidity on the Friction and Wear Properties of Ceramic Materials. J. Tribol. 1992, 114, 131-140. [CrossRef]

14. Shen, Y.J.; Mi, S.T.; Sun, L.; Yang, L.Y.; Gong, H.R. Mechanical properties and dislocation evolution of Cu-Fe interfaces from molecular dynamics simulation. Mater. Chem. Phys. 2021, 262, 124270. [CrossRef]

15. Wang, M.J.; Zhang, G.W.; Xu, H.; Dong, Y.; Sun, F.E.; Fu, Y.Z. Density functional theory investigation on the stability, adhesion strength, tensile properties and fracture behavior of $\gamma$-Fe/Cu heterogeneous nucleation interface. Results Phys. 2021, $24,104143$. [CrossRef]

16. Xu, X.; Song, K.; Du, S. Friction and wear behavior of copper-base powder metallurgical material under in the Presence of Electric Current. Mater. Prot. 2008, 41, 66-68.

17. Qian, Z. Research on powder metallurgy pantograph strips for electrical locomotive. Powder Metall. Ind. 2007, $17,43-46$.

18. Gao, X. Research on Copper Based Powder Metallurgical Friction Materials Suitable to Drill Rig. Master's Thesis, China University of Geosciences, Beijing, China, 2011.

19. Fang, S. Effects of Cr on Friction and Wear Properties of Cu-Based Powder Metallurgy Material. Master's Thesis, Dalian Jiaotong University, Dalian, China, 2013.

20. Fu, R.; Fang, S.; Gao, F.; Han, X. Effects of Cr content on friction and wear properties of copper matrix frictional materials. Lubr. Eng. 2013, 38, 15-20.

21. Chen, X.; Zhou, H.; Zhang, T.; Bi, L.; Tian, W.; Fu, S.; Li, W.; Liu, X.; Ma, F.; Zhang, K.; et al. Mechanism of interaction between the $\mathrm{Cu} / \mathrm{Cr}$ interface and its chemical mixing on tensile strength and electrical conductivity of a Cu-Cr-Zr alloy. Mater. Des. 2019, 180, 107976. [CrossRef]

22. Gong, T.; Yao, P.; Xiong, X.; Zhou, H.; Zhang, Z.; Xiao, Y.; Zhao, L.; Deng, M. Microstructure and tribological behavior of interfaces in $\mathrm{Cu}-\mathrm{SiO}_{2}$ and $\mathrm{Cu}-\mathrm{Cr}$ metal matrix composites. J. Alloys Compd. 2019, 786, 975-985. [CrossRef]

23. Xu, Y. Principles of Metals; Metallurgical Industry Press: Beijing, China, 2020.

24. Hämäläinen, M.; Jääskeläinen, K.L.R. A thermodynamic analysis of the binary alloy systems Cu-Cr, Cu-Nb and Cu-V. Calphad 1990, 14, 125-137. [CrossRef]

25. Wen, S.; Huang, P. Principles of Tribology, 4th ed.; Tsinghua University Press: Beijing, China, 2017.

26. Futami, T.; Ohira, M.; Muto, H.; Sakai, M. Contact/scratch-induced surface deformation and damage of copper-graphite particulate composites. Carbon N. Y. 2009, 47, 2742-2751. [CrossRef]

27. Williams, J.A. Analytical models of scratch hardness. Tribol. Int. 1996, 29, 675-694. [CrossRef]

28. Xiao, J.K.; Zhang, L.; Zhou, K.C.; Wang, X.P. Microscratch behavior of copper-graphite composites. Tribol. Int. 2013, 57, 38-45. [CrossRef]

29. Ji, G. Principle of Friction and Wear; Agricultural Press: Beijing, China, 1992. 